\title{
Meridional overturning and large-scale circulation of the Indian Ocean
}

\author{
Alexandre Ganachaud ${ }^{1}$ \\ Massachusetts Institute of Technology/Woods Hole Oceanographic Institution Joint Program in \\ Physical Oceanography, Cambridge
}

\begin{abstract}
Carl Wunsch and Jochem Marotzke ${ }^{2}$
Department of Earth, Atmospheric and Planetary Sciences, Massachusetts Institute of

Technology, Cambriclge
\end{abstract}

John Toole

Woods Hole Oceanographic Institution, Woods Hole, Massachusetts

\begin{abstract}
The large scale Indian Ocean circulation is estimated from a global hydrographic inverse geostrophic box model with a focus on the meridional overturning circulation (MOC). The global model is based on selected recent World Ocean Circulation Experiment. (WOCE) sections which in the Indian Basin consist. of zonal sections at $32^{\circ} \mathrm{S}, 20^{\circ} \mathrm{S}$ and $8^{\circ} \mathrm{S}$, and a section between Bali and Australia from the Java-Australia Dynamic Experiment (JADE). The circulation is required to conserve mass, salinity, heat, silica and "PO" $\left(170 \mathrm{PO}_{4}+\mathrm{O}_{2}\right)$. Near-conservation is imposed within layers bounded by neutral surfaces, while permitting advective and diffusive exchanges between the layers. Conceptually, the derived circulation is an estimate of the average circulation for the period 1987-1995. A deep inflow into the Indian Basin of $11 \pm 4 \mathrm{~Sv}$ is found, which is in the lower range of previous estimates, but consistent with conservation requirements and the global datia set. The Indonesian Throughflow (ITF) is estimated at $15 \pm 5 \mathrm{~Sv}$. The flow in the Mozambique Channel is of the same magnitude, implying a weak net flow between Madagascar and Australia. A net evaporation of $-0.6 \pm 0.4 \mathrm{~Sv}$ is found between $32^{\circ} \mathrm{S}$ and $8^{\circ} \mathrm{S}$, consistent with independent estimates. No net heat gain is found over the Indian Basin $\left(0.1 \pm 0.2 \mathrm{PW}\right.$ north of $\left.32^{\circ} \mathrm{S}\right)$ as a consequence of the large warm water influx from the ITF. Through the use of anomaly equations, the average dianeutral upwelling and diffusion between the sections are required and resolved, with values in the range $1-3 \times 10^{-5} \mathrm{~cm} \mathrm{~s}^{-1}$ for the upwelling and $2-10 \mathrm{~cm}^{2} \mathrm{~s}^{-1}$ for the diffusivity.
\end{abstract}

\section{Introduction}

The meridional overturning circulation of the Indian Ocean has been the subject of a number of recent papers [Fu, 1986; Toole and Warren, 1993; Robbins and Toole, 1997; Macdonald, 1998; Lee and Marotzke, 1997, 1998; Zhang and Marotzke, 1999]. Although the meridional overturning rate and structure are a basic descriptive feature of the general circulation as well as a determinant of the heat and other property fluxes, there remains significant disagreement about both its qualitative and quantitative features in the Indian Ocean.

\footnotetext{
${ }^{1}$ Now at Institut Français de Recherche pour l'Exploitation de la Mer, Plouzané, France.

${ }^{2}$ Now at Sonthampton Oceanography Centre, University of Southampton, Southampton, England.
}

Copyright 2000 by the American Geophysical Union.

Paper number 2000JC900122

0148-0227/00/2000JC900122\$09.00
(Here the expression "meridional overturning circulation" is used to denote the net zonally integrated stream function of the depth/mericlional plane. There is no implication that it is restricted to a single top-to-bottom cell; the vertical structure is to be determined. Its strength will, however, sometimes be measured by the net inflow of deep waters.)

Here we wish to discuss the extent to which this element of the circulation is in fact determinable with existing datia, and to place some bounds on the Indian Ocean heat and freshwater flux divergences. The context of the discussion is the estimated global circulation from a recent inversion by Ganachaud [1999]; Ganachaud and Wunsch[2000]. This work follows the earlier global calculations of Macdonald and Wunsch [1996] and Macdonald [1998], but with the datia almost entirely replaced by the recent, hydrographic sections from the World Ocean Circulation Experiment (WOCE); see inset of Figure 1.

From a hydrographic section at $18^{\circ} \mathrm{S}$, Warren [1981] estimated a northward flow of $19 \mathrm{~Sv}$ in the deep western 


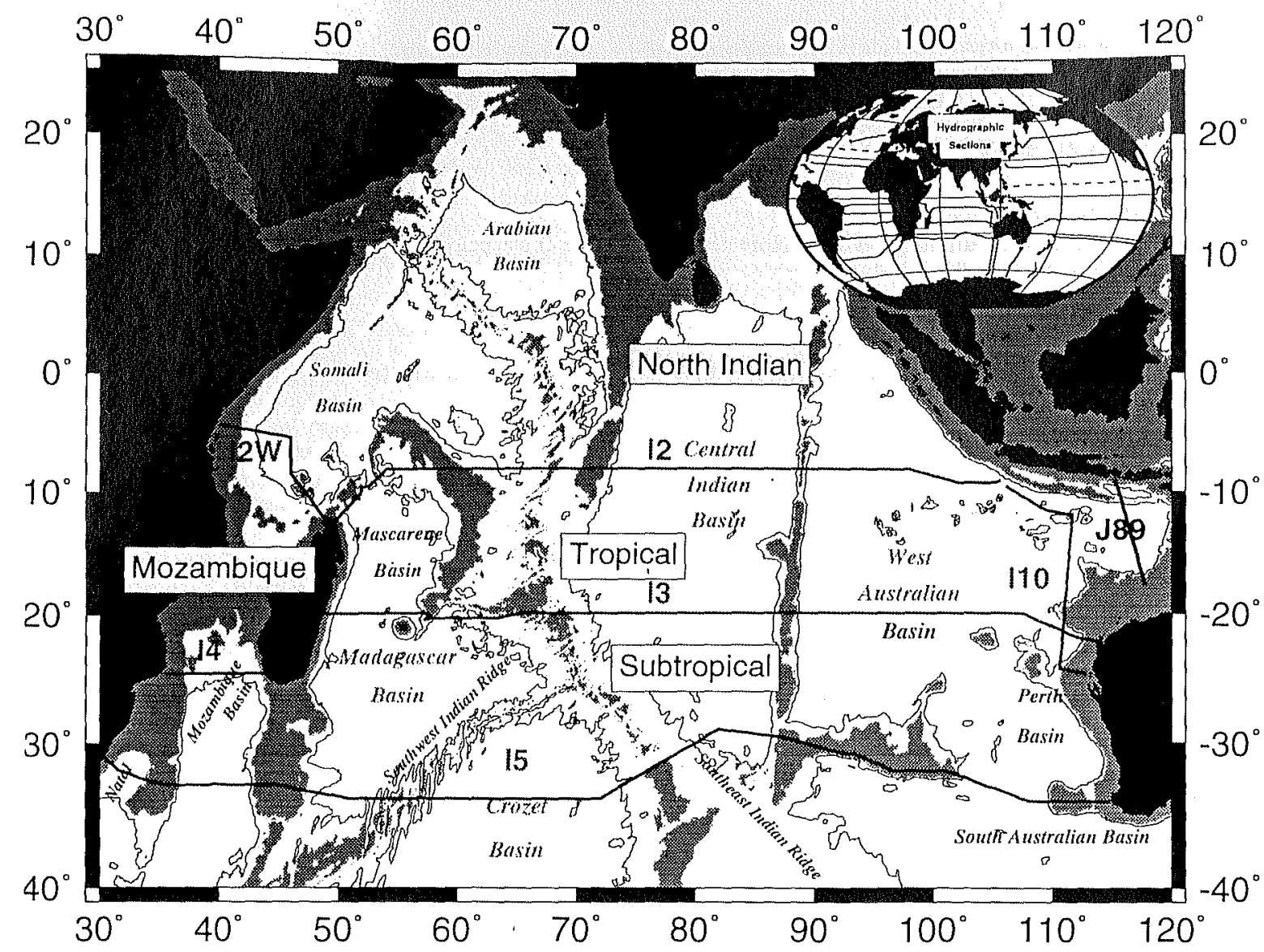

Figure 1. Indian Ocean sections and topography (adapted from Robbins and Toole, [1997]). The 4000- $\mathrm{m}$ isobath is contoured, and areas shallower than $3000 \mathrm{~m}$ are shaded. Box names are indicated in the shaded rectangles. The hydrographic lines of the global model are indicated in the inset. Most were occupied within the WOCE program.

boundary currents. Fu [1986], using the same section, but combining it with four other sections in the Indian Ocean and doing a formal inverse calculation, found a weak deep water inflow of $3.6 \mathrm{~Sv}$, with the bulk of the northward flow occurring at intermediate levels (10002000 dbar). In contrast, Macdonald [1998], again with the same $18^{\circ} \mathrm{S}$ section but combined with a global data set containing more recent sections than were available to $\mathrm{Fu}$ (notably at $32^{\circ} \mathrm{S}$ ), obtained $10 \mathrm{~Sv}$ of deep water northward flow with a $5 \mathrm{~Sv}$ southward flow at intermediate levels.

Using the pre-WOCE 1987 section at $32^{\circ} \mathrm{S}$ and tracer properties to suggest a zero-velocity surface, Toole and Warren [1993] estimated the surprisingly large bottom water flux below 2000 dbar of $27 \pm 10 \mathrm{Sy}$ geostrophically. Robbins and Toole [1997] recognized that this large flux would cause problems with the silica budget, and added silica conservation as a constraint. They obtained, through an inverse calculation, a weaker deep influx of $12 \pm 3 \mathrm{~Sv}$. At the two standard deviation level, this value is inconsistent, with the non-silica-conserving

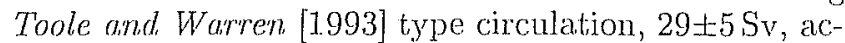
cording to the Robbins and Toole [1997] error analysis. Assuming the error estimates are appropriately computed, the inconsistency implies systematic (non ran- dom) errors present in the models. In both circulations the intermediate waters (1000-2000 dbar) moved southward. H. Bryden and L. Beal (Role of the Agulhas Current in Indian Ocean circulation and associated heat and freshwater fluxes, submitted to Deep-Sea Research, 2000; hereafter Bryden and Beal, submitted manuscript, 2000) showed that the inferred overturning and heat budget, were both sensitive to the assumed strength of the Agulhas Current, and notably to the presence of a northward flowing undercurrent as detected by acoustic Doppler current profiler (ADCP) measurements.

Lee and Murotzhe [1997, 1998], using a general circulation model (GCM), climatological hydrography, and surface fluxes, inferred a mean northward overturning flow of $14 \mathrm{~Sv}$ in the upper $1000 \mathrm{~m}$ with a weak south-tonorth deep water flow. Their solution is consistent with several other GCM calculations that exhibit weak deep inflow, but a vigorous shallow overtuming (see Zhang and Marotzkic [1999], for a review). Such a shallow overturning conflicts with the direction of the flow as would be suggested by a classical water mass analysis [e.g., Toole and Warten, 1993].

Here, we seek to address the question of whether a, consistent zonally integrated circulation can be found 
in the face of the apparent contradiclions in the various existing estimates. We attempti to distinguish quantitatively between properties of the circulation which are the direct consecuence of the hydrographic field or other direct measurements, and those which have cmerged as "known" through the process of assumption and tradition.

\section{Method}

The basic procedure is that of the steady geostrophic box inversions described by Wunsch [1996], and as employed previously in this ocean by Fu [1.986], Macdonald [1998], Macdonald and Wunsch [1996], etc., with a number of significant improvements. A full discussion of the changes was presented by Ganachaud [1999] (hereafter G99), but the major modifications from previously published inversions include the following:

1. Neutral surfaces [McDougall, 1987; Jackett and McDougall, 1997] are used instead of isopycnals, with calculation, as part of the inversion, of the clianeutral transfers, dianeutral mixing of tracers, and freshwater fluxes, along with the reference velocities and ageostrophic transport adjustment in the uppermost layer (ascribed to the Elman transport uncertainty).

2. We use a more quantitative constraint error budget derived from a study of the $1 / 4^{\circ}$ nominal lateral resolution GCM run at the U.S. Naval Post Graduate School see Semtner and Chevinin, 1992; Stammer et al., 1996; G99]. In this study the variability of fluxes computed from near-synoptic sections could be compared to that of the true mean. This variability clominates the error budget of inversions done using the section data. An important example is the very large estimated potential deviation of silica flux from its long-term average value when computed from any particular section.

3. We use conservation equations in terms of property anomalies [e.g., McDougall, 1991; McIntosh and Rintoul, 1997] rather than full property values themselves (see section A.3 in Appendix A), but based upon making explicit the necessary assumptions concerning the error covariance between mass constraints and property constraints [Wunsch, 1996, p.273; G99].

4. Mean wind fields derived from the National Center for Environmental Prediction (NCEP) reanalysis [Kalnay et al., 1996] are used.

5. The nutrient and oxygen divergences are determined (A. Ganachaud and C. Wunsch, Oceanic nutinent and oxygen fluxes during WOCE and boundaries on export production, submitted to Global Biogeochemical Cycles, 2000).

We start the discussion with a list of the difficulties and unknowns of the circulation in the Indian Ocean (section 3). The model setup (section 4) and resulting circulation are then described (section 5 ) with sensitivity experiments (section 6). The heat and freshwater budgets are discussed in section 7 , followed by conclusions.

\section{Indian Ocean Problems}

The Indian Ocean is complex, and a full discussion of the details of the circulation as previously described would be very lengthy. Here we will only summarize some of the major moncrainties most directly affecting the inversion.

\subsection{Monsoonal Effects}

Becanse of the intense monsoonal shitts, cliscussion of the Indian Ocean as a steady state system is problematic; our main excuse for nonelheless doing so is that below the top lew hundred meters, where our nncertainties are large, and away from the Somali Cument, there is no evidence of a significant anmual shift in hydrography or baroclinic How field [e.g., Warren and Johnson, 1992; Freqx et al., 1986]. (Fieur et al. [1986] fomd a. variation of $30 \%$ in the deep western boundary current transport at $10^{\circ} \mathrm{N}$, which may be due to internal wave noise (G99)). There is also the weight of history: All previous non-GCM discussions have assumed that tieating the ocean as though approximately steady is sensible, but one must be wary of this assumption in reading the literature. In the present, analysis, variability is accounted for in the uncertiainties, based on the Semtner and Chervin [1992] model output (Appendix A and C99].

The most spectacular time-dependent feature is the establishment and shutidown of the Somali Current, whose net transport at the equator ranges from 0 to $21 \mathrm{~Sv}$ (including undercurrents) [Schott et al., 1990]. However, the GCM of Lee and Marotzke [1998] suggested that the upper ocean variability decreases toward the south (away from the Mozambique Channel). They estimated a monsoonal variability in the depth-latitude stream function of $\pm 20 \mathrm{~Sv}$ with associated changes in the meridional heat flux of $\pm 1.8 \mathrm{PW}$. But most of the stream function variations were explained by a barotropic response to Ekman transport variations, with a relatively small contribution from the vertical shear ( $\pm 2 S_{v}$ or less away from their southern sponge layer). (The Somali Current region was exceptional; there the vertical shear contribution was large, of order $10 \mathrm{~Sv}$.) Barotropic fluctuations are not aliased in the hydrography so that a model using the mean Ekman flux can be combined consistently with sections taken at different seasons. The variability in the baroclinic field is accounted for as part of the noise.

Nonlinear interactions of the time-dependent, depthindependent transports could conceivably generate significanti rectified mean flows. Lee and Marotzke [1998] could, however, find no such effect in the heat flux.

\subsection{Agulhas Current and Mozambique Channel}

The gyral subtropical circulation is closed by the Agulhas Current, believed to transport between 66 and $70 \mathrm{~Sv}$ [Beal and Bryden, 1997]. Stramma and Lutjeharms [1997] suggested that most of the Agulhas waters are fed by the subtropical gyre (e.g., their Figure 7), but with a fraction (20-25 Sv) from either the Mozambique Channel or the East Madagascar Current. Of these, Stramma and Lutjeharms [1997] and Sotre and da Silva [1984] suggested the latiter was the more important, while Lutjeharms [1976] concluded that the Mozambique Current is the major source of Agulhas wa- 
ters. Satre and da Silva [1984] found no continuous upper ocean current, in the Mozambique Channel and litthe contribution to the Agulhas Current. This inference was in agreement with the study of Ménaché [1963], who believed that the Mozambique Current curved eastward and flowed back to the north along the west coast of Madagascar. Recent conductivity-temperature-depth (CTD) data and satiellite imagery showed that the Agulhas Current is partly fed by the Mozambique Current, and partly by a westward flow south of Madagascar [Griindlingh, 1993 ].

Fu's [1986] inverse box model produced a net southward flux of $6 \mathrm{~Sv}$ in the Mozambique channel, similar: to that of Stramma and Lutjeharms [1997]. (The vertical structure of the derived flow north and south of the Channel implied large imbalances in individual layers, possibly due to the seasonal variability.) The global inversion of Macdonald [1998] did not produce any significant flux there.

The flow through the Mozambique Channel appears to be highly variable on seasonal timescales. Measurements from tide gauges combined with hydrography [Donguy and Piton, 1991] show an annual cycle with $\pm 10 \mathrm{~Sv}$ amplitude in the channel. Altimetric data (not shown) examined by us show fluctuations of $\pm 25 \mathrm{~cm}$ in the sea surface height difference between south Madagascar and Africa $\left(25^{\circ} \mathrm{S}\right)$. Assuming a linear decrease of the velocity down to 1000 dbar, the implied variations in the net geostrophic transport are $\pm 20 \mathrm{~Sv}$. (This calculation gives only an order of magnitude estimate, but the 1000 dbar vertical scale and the linear decrease are consistent, with the solution described below. Baroclinic Kelvin waves may account for these rapid fluctuations. Seasonal variability is probably also present in the density field, as observed in the GCM of Lee and Marotzke [1998] in the Somali region.)

\subsection{Indonesian Throughflow (ITF)}

The Pacific-to-Indian Ocean property flux (Indonesian Throughflow, hereafter ITF) is highly variable and poorly sampled. If its average mass transport were 10 Sv at $20^{\circ} \mathrm{C}$ and assuming that it ultimately leaves the Indian Ocean at $10^{\circ} \mathrm{C}$, it would produce a convergence of $0.4 \mathrm{PW}$ in the Indian Ocean heat transport budget. This flux convergence is of the same size as the total climatological heat input to the Indian Ocean by air-sea exchanges [Oberhuber, 1988] .

The published estimates of the net ITF mass transport range from $18 \pm 7 \mathrm{~Sv}$ westward to $2.6 \mathrm{~Sv}$ eastward [Fieur et al., 1996], with a host of estimates between these two extremes, depending upon the measurement time and method [Godfrey, 1996]. Macdonald [1998] constrained her inverse model to a net ITF of $10 \pm 10 \mathrm{~Sv}$ and obtained, after inversion, a flux of $9 \pm 7 \mathrm{~Sv}$. If not specifically constrained, her model produced a net ITF of $11 \pm 14 \mathrm{~Sv}$. Her sensitivity experiments (ITF = OSv; $\mathrm{ITF}=20 \mathrm{~Sv}$ ) also showed that large variations in the ITF strength had no effect on her estimated Agulhas Current and Drake Passage fluxes. Nevertheless, such changes affect dramatically regional property budgets and the derived air-sea exchanges in the Indian and $\mathrm{Pa}$ cific Oceans. Zhang and Marotzke. [1999] estimated the ITF from climatological Indian Ocean hydrography and a. GCM, and found that a small mean inflow (2.7 Sv) was sufficient, to close the Indian Ocean heat and salt, balance.

The strength of the ITF is plausibly dependent upon the phase of El Niño Southern Oscillation (ENSO, e.g., Wajsowicz [1994, 1996], who used a numerical model; and Gordon et al. [1999], who used current meter data). From expandable batythermograph (XBT) time series and historical datia, Meyers et al. [1995] found a total mean transport in the upper $400 \mathrm{~m}$ of $5 \mathrm{~Sv}$ to the west with a $\pm 2.5 \mathrm{~Sv}$ variation in the annual cycle They estimated a top-to-botitom mean transport of $7 \mathrm{~Sv}$. Moorings in the Makassar Strait, which is believed to be the main path of the throughflow, showed an annual average transport of $9 \mathrm{~Sv}$ in 1997 with variations from $5 \mathrm{~Sv}$ during El Niño to $12 \mathrm{~Sv}$ during La Niña [Gordon et al., 1999]. For present purposes, we use a throughflow of $7 \pm 7 \mathrm{~Sv}$ as the initial best estimate. (To account for variability and measurement, noise, the actual constraint on the ITF between Indonesia and Australia is $7 \pm 15 \mathrm{~Sv}$, as explained in section 4.2.)

\section{The Model}

\subsection{Data and Treatment}

Figure 1 shows the Indian Ocean sector of the model which is made of the WOCE sections I2 (December 1995 to January 1996 [e.g., Johnson et al., 1998]), I3 (April-June 1995), I4 (June 1995) and I10 (NovemberDecember 1995 [Bray et al,,1997]), the pre-WOCE section I5 (November 1987 [Toole and Warren, 1993; Robbins and Toole, 1997]), and the Java Australia Dynamic Experiment (JADE) section (August 1989 [Fieux et al., 1994; Coatanoan., 1997]). G99 discussed various problems with the data, particularly from noise in sections close to the equator and some sampling problems in the JADE data. (The $1989 \mathrm{JADE}$ data were used instead of the 1992 data because they included nutrient measurements. However, the 1989 data were combined with a station of the 1992 data to complete the section, as suggested by the sensitivity experiments discussed below (section 5.3.))

\subsection{Layers and Constraints}

Constrained boxes are defined (Figure 1) for the Indian Ocean as the "subtropical box" (I5, I4, I3), the "Mozambique Channel box" (I4, I2W), the "tropical box" (I3, I2, I10), and the "north Indian box" (I2W, I2, I10, J89). Note that the north Indian box includes the area between I10 and J89 because the I10 section could not be completed up to the Indonesian coast. The layers, defined by neutral surfaces (Table 1), were chosen to facilitate the comparison with the existing literature, to match the Southern Ocean layers of the global model, and to have a relatively homogeneous thickness over the basin. Mass conservation was required consistent with the error budget of G99 (Table 2). Those uncertainties take into account the error due to oceanic variability (through a GCM-based simulation) and internal waves (from the Garrett and Munk [1972] spectrum). The resulting a priori uncertainties that characterize the net transports range from $\pm 7 \mathrm{~Sv}$ at $32^{\circ} \mathrm{S}$ to $\pm 15 \mathrm{~Sv}$ on the 
Table 1. Indian Ocean Neutral Surface Layers $\left(\gamma^{n}\right)^{a}$

\begin{tabular}{|c|c|c|c|c|}
\hline Layer & $\begin{array}{l}\text { Upper } \\
\text { Interface }\end{array}$ & $\begin{array}{l}\text { RT97 } \\
\text { Layer }\end{array}$ & $\begin{array}{l}\text { 15 Interface Property } \\
\text { From RT97 }\end{array}$ & $\begin{array}{l}\text { Watier Mass } \\
\text { Name }\end{array}$ \\
\hline $\begin{array}{l}1 \\
2\end{array}$ & $\begin{array}{l}\text { Surface } \\
\gamma^{n}=25\end{array}$ & $1^{\mathrm{b}}$ & & Surface Water \\
\hline 3 & $\gamma^{n}=26.2$ & $2^{b}$ & & Subantarctic: Mode Water \\
\hline 4 & $\gamma^{n}=26.9$ & 3 & $\sigma_{\theta}=26.80 ; \theta=9.85$ & Upper Antarctic Mode Water \\
\hline 5 & $\gamma^{n}=27.36$ & 4 & $\sigma_{\theta}=27.20 ; \theta=4.65$ & Lower Antarctic Mode Water \\
\hline 6 & $\gamma^{n}=27.7$ & 5 & $\sigma_{2}=36.65 ; \theta=3.26$ & Upper Deep Water \\
\hline 7 & $\gamma^{n}=27.96$ & $6^{\mathrm{c}}$ & $\sigma_{2}=36.92 ; \theta=2.20$ & Lower Deep Water \\
\hline 8 & $\gamma^{n}=28.07$ & & & \\
\hline 9 & $\gamma^{n}=28.11$ & $7^{c}$ & $\sigma_{d}=45.89 ; \theta=1.28$ & Upper Bottom Water \\
\hline 10 & $\gamma^{n}=28.15$ & & & \\
\hline 1.1 & $\gamma^{n}=28.23$ & 8 & $\sigma_{\mathrm{d}}=46.01 ; \theta=0.43$ & Lower Bottiom Water \\
\hline
\end{tabular}

"Values are in kilograms per cubic meter. For comparison, the Robbins and Toole [1997] layers are indicated along with the potential density and temperatures at each interface (from their Table 1).

bThese layers have a slightly different interface from that of RT97 $\left(\gamma^{n}=26.20\right.$ instead of 26.50).

cThis RT97 layer corresponds to two layers in this study.

JADE 89 ITF section. The Ekman transports from the NCEP reanalysis [Kalnay et al., 1996] with their a priori uncertainties are listed in Table 3 . Because of the large baroclinic variability in the East African Coastal Current (EACC) on section I2W, a large adjustment $( \pm 20 \mathrm{~Sv})$ was allowed to the flow in the first layer.

A horizontal average representation of advective $\left(w^{*}\right)$ and diffusive $\left(\kappa^{*}\right)$ dianeutral transfers is allowed between the layers and for each property. The same $w^{*}$ and $\kappa^{*}$ is used for all properties, and no diffusion is allowed in the mass equations. The horizontal average property and property gradients on a neutral surface are calculated from the bounding sections.

Top-to-bottom silica is conserved as suggested by previous authors [e.g., Robbins and Toole, 1997 (hereafter RT97)] (see G99 for a quantitative justification). The permitted error for the basin silica balance is about, $\pm 700 \mathrm{kmols}^{-1}$, which is 7 times larger than that used by RT97, but according to G99, is a more accurate represent,ation of the actual variability in the advective silica flux (Appendix A.2). This estimated variability was calculated by defining a pseudosilica field in the GCM from known covariances of silica with temperature and salinity (G99 and Appendix A). For the standard exper- iment presented below, salt is conserved top-t;o-bottom and within individual layers. Heat and the tracer combination "PO" $=170 \mathrm{PO}_{4}+\mathrm{O}_{2}$ [Redfield et al., $1963 ; \mathrm{An}$ derson and Sarmiento, 1994], are conserved only in layers below the surface. (The surface layer is nonconservative because of heat and oxygen exchanges with the atmosphere.) The value 170 for the PO Redfield ratio is controversial [e.g., Broecker et al., 1985; Minster and Boulahdid, 1987]. However, an experiment with a lower ratio of 140 produced a similar solution. The freshwater flux was not constrained, but was solved for through the inversion. Again the a priori uncertainties are consistent with the error budget of G99, taking into account the oceanic circulation variability. Following McDougall [1991] and Wijffels [1993], conservation equations for heat, salt, and PO are written as anomaly equations, that is, the mass divergence time the average property concentration is subtracted from the original conservation equation (see section A.3).

The Indian Ocean topography is complex (Figure 1), and the deep layer fluxes were broken down and constrained according to the bathymetric features. These "bathymetric constraints" are listed in Table 4. Unlike the RT97 inversion, the net bottom water flow into the

Table 2. A Priori Uncertainties in the Mass Conservation Equations ${ }^{a}$

\begin{tabular}{lccccc}
\hline & Subtropical Box & Mozambique Box & Tropical Box & North Indian Box & Indian Box \\
\hline Sections & I5-I4-I3 & I4-I2W & I3-I2-I10 & I2W-I2-I10-J89 & J89-I5 \\
Total & 14 & 16 & 16 & 25 & 15 \\
Layers 1-4 & 8 & 10 & 8 & 10 & N/A \\
Layers 5-6 & 4 & 4 & 4 & 8 & N/A \\
Layers 7-11 & 2 & 3 & 2 & 4 & N/A
\end{tabular}

\footnotetext{
aValues represent one standard deviation and are given in sverdrups. A constraint on the basin-wide top-to-bottom mass conservation was added to the constraints over individual boxes. The uncertainty is mainly due to oceanic circulation variability and internal waves (from the error budget of G99).

${ }^{\mathrm{b}} \mathrm{N} / \mathrm{A}$ denotes not applicable.
} 
Table 3. Initial Ekman Transport and That Derived From the Model (Final) ${ }^{\text {a }}$

\begin{tabular}{cccc}
\hline Section & Tnitial & Final & percent Correction \\
\hline I5 & $0.3 \pm 1$ & $0.5 \pm 1$ & - \\
14 & $-0.5 \pm 1$ & $-0.5 \pm 1$ & - \\
I3 & $-11.5 \pm 5$ & $-10 \pm 4$ & $-8 \%$ \\
I2W & $-4.5 \pm 20$ & $9 \pm 9$ & $-300 \%$ \\
I2 & $-11.6 \pm 5$ & $-11 \pm 5$ & $-6 \%$ \\
110 & $-2.9 \pm 1$ & $-2.9 \pm 1$ & $0 \%$ \\
J89 & $-0.65 \pm 1$ & $-0.6 \pm 1$ & -
\end{tabular}

The adjustments apply to the total transport in the first layers, including in principle any deviation from the time mean geostrophic transport (e.g., monsoonal variability). The relative amplitude of the adjustment is indicated for transports larger than 1 Sv.

Crozet and Perth basins is not constrained to be northward. This change is discussed further below. The fux into the Mozambique basin was weakly constrained to be northward ( $1 \pm 2 \mathrm{~Sv}$ ). The flux below $1300 \mathrm{dbar}$ in the ITF was constrained to be small as this level colresponds to the limit of the waters of Indonesian origin [Fieux et al., 1994].

\subsection{Reference Surfaces and Dianeutral Terms}

The initial zero-velocity surfaces, called "reference surfaces", are indicated in Table 5 . The 5 reference surface was taken from the RT97/ Toole and Warren [1993] (hereafter TW93) initial guess with a modification close to the coast in the Agulhas Cument region to account for the presence of an Agulhas Undercurrent [Beal and
Bryden, 1997, Figure 3]. In general, a deep reference suface was preferred to a shallow one to clecrease the potentially large velocity errors at depth, which can result in an eddy-induced vertical shear region. The northward moving botion waters in the abyssal Indian Ocean lie in the potential temperature range $-0.8^{\circ}$ to $1.4^{\circ} \mathrm{C}$ in the western basin and $0^{\circ}$ to $1^{\circ} \mathrm{C}$ in the eastem basin [Schmitz, 1996, p. 122]. Therefore the interface between the Circumpolar. Deep Water and the "Indian Ocean Deep Water" defined by $\gamma^{n}=28.11\left(\theta=1.2^{\circ}\right.$ at $20^{\circ} \mathrm{S}$ ) was chosen as a "first guess" for the I2, I3, and 110 reference suface (a similar suface was chosen by other authors, [e.g., Johnson ct al., 1998, Table 1]). The model is not crucially dependent upon this choice: An experiment, which started with a botiom reference surface for those sections produced a very similar flow after inversion. Strong shear down to $3000 \mathrm{dbar}$ in the composite JADE section led to the choice of a bottom reference surface, with the bathymetric constraint ensuring no net flow in individual layers below the sill depth $\left(\gamma^{n}=27.7,1300\right.$ dbar $)$ by adjusting the reference velocities accordingly.

In common with previous inverse solutions, the small scales of the reference velocity $\left(b_{i}\right)$ are not resolved, and the posterior uncertainties on the inclividual $b_{i}$ are almost unchanged from the prior values. The a priori uncertainties were given a minimum value of $\pm 1 \mathrm{~cm} \mathrm{~s}^{-1}$ and increased according to the local shear and when cument meter: data suggested it [Dickson, 1989, pp. E9, E-11; Schott et. al., 1988].

A large range of adjustment was allowed to dianeutral transfers $w^{*}\left( \pm 10^{-3} \mathrm{~cm} \mathrm{~s}^{-1}\right)$ and mixing coefficients $k_{i}^{*}$ $\left( \pm 100 \mathrm{~cm}^{2} \mathrm{~s}^{-1}\right)$. These a priori values are near the upper limit of, or larger than, published estimates [e.g., TW93; RT97; Polzin et al., 1997; Munk and Wunsch, 1998], leaving the model free to determine the coef-

Table 4. "Bathymetric" Constraints on the Flux in Layersa

\begin{tabular}{|c|c|c|c|c|}
\hline Name & Section & Layer (Depth) & Net Flux & Longitude \\
\hline $\begin{array}{l}\text { Natal valley } \\
\text { Mozambique basin } \\
\text { Madagascar basin } \\
\text { Central basin } \\
\text { Mozambique sill depth } \\
\text { ITF sill, mass } \\
\quad \text { sill, silica }\end{array}$ & $\begin{array}{c}\mathrm{I} 5 \\
\mathrm{I} 5 \\
\mathrm{I} 5 \\
\mathrm{I} 5 \\
\mathrm{I} 4 \\
\mathrm{~J} 89\end{array}$ & $\begin{array}{l}\text { 9-10 (3400dbar) } \\
9-11 \text { (3500dbar) } \\
9-11 \text { (3600dbar) } \\
9-11 \text { (4000dbar) } \\
8-11 \text { (2800dbar) } \\
6-10 \text { (1300dbar) } \\
\text { each layer } \\
\text { total } \\
\text { each layer }\end{array}$ & $\begin{array}{l}0 \pm 0.5 \\
1 \pm 2 \\
0 \pm 5 \\
0 \pm 1 \\
0 \pm 0.5 \\
0 \pm 6 \\
0 \pm 3 \\
0 \pm 140^{\mathrm{b}} \\
0 \pm 70^{\mathrm{b}}\end{array}$ & $\begin{array}{l}30^{\circ} \mathrm{E} \text { to } 34^{\circ} \mathrm{E} \\
35^{\circ} \mathrm{E} \text { to } 46^{\circ} \mathrm{E} \\
46^{\circ} \mathrm{E} \text { to } 56^{\circ} \mathrm{E} \\
78^{\circ} \mathrm{E} \text { to } 89^{\circ} \mathrm{E} \\
\text { full section } \\
\text { fill section }\end{array}$ \\
\hline Name & Sections & Layer (Depth) & Net Divergence & Longitude \\
\hline $\begin{array}{l}\text { Mozambique basin } \\
\text { Perth basin } \\
\text { Mascarene basin } \\
\text { West Australian basin }\end{array}$ & $\begin{array}{c}\mathrm{I} 5 / \mathrm{I} 4 \\
\mathrm{I} 5 / \mathrm{I} 3 \\
\mathrm{I} 3 / \mathrm{I} 2 \\
\mathrm{I} 3 / \mathrm{I} 2 \mathrm{I} 10\end{array}$ & $\begin{array}{l}\text { 8-11 (2800dbar) } \\
9-11 \text { (3500dbar) } \\
8-11 \text { (3000dbar) } \\
8-11 \text { (3000dbar) }\end{array}$ & $\begin{array}{l}0 \pm 2 \\
0 \pm 4 \\
0 \pm 4 \\
0 \pm 4\end{array}$ & $\begin{array}{l}35^{\circ} \mathrm{E} \text { to } 46^{\circ} \mathrm{E} / \mathrm{Full} \text { I } 4 \\
96^{\circ} \mathrm{E} \text { to end } / 87^{\circ} \mathrm{E} \text { to end } \\
49^{\circ} \mathrm{E} \text { to } 58^{\circ} \mathrm{E} / 49^{\circ} \mathrm{E} \text { to } 59^{\circ} \mathrm{E} \\
96^{\circ} \mathrm{E} \text { to end } / 89^{\circ} \mathrm{E} \text { to end }\end{array}$ \\
\hline
\end{tabular}

\footnotetext{
"The constraints are imposed on either the total flux through a single section (upper part, positive northward) or on the divergence between two sections (lower part). The layer and approximative depth below which the flux is constrained are indicated along with the uncertainty on the net flux (single section) or divergence (between sections) (in Sv).

buits are in kilomoles Si per second.
} 
Table 5. Initial Zero-Velocity Surface, or Reference surfaces

\begin{tabular}{lll}
\hline Section & Reference Surface & \multicolumn{1}{c}{ Remark } \\
\hline 15 & station-specific & TW93/BealeBryden [1997] \\
14 & 2500 dbar & Mozambicue sill deptil \\
$12 W$ & bottiom & see text; \\
$12,13,110$ & $\gamma^{n}=28.11$ & RTg7/TW93 \\
J89 & bottiom & see text
\end{tabular}

ficients from the constiaints. However, both upwelling and mixing turn out to be well determined by the heat and salt anomaly conservation requirements, and the final values have smaller amplitudes than the a priori ranges. No positivity requirement, was set for $k$.

\section{Indian Ocean Circulation}

The full inversion is a global one (inset of Figure 1; Ganachaud and Wunsch [2000]). A number of solutions were explored by changing the model configuration, and focusing on the overturning circulation. The "stanclard" solution employs property anomalies and the constraints listed in Table 6. Alternative solutions will be described briefly in the discussion. The solution for the reference velocities, the dianeutial advective and diffusive transfers, the adjustment to Ekman transport, and the freshwater fluxes is obtained using the Gauss-Markov estimator [e.g., Wunsch, 1996, p. 184], which produces a minimum error variance solution. The posterior error covariance includes the part that is not resolved by the equations, in contrast with the conventional least squares and usual singular value decomposition estimators.

Although water mass distributions guided our choice of the "first guess" circulation, the flow was not explicitly constrained to force the net layer fluxes to be advected away from their supposed sources. In several places the large-scale estimated flow, although indistinguishable from zero within error bars, does not follow the large-scale property distributions in the Wüstian sense; that is, away from the core of boundary currents, the mean mass flux direction does not always coincide with the direction implied by the mean property tongues. Given the existence of an eddy field and its potential effects on property distributions, the only reasonable constraints appear to be enforcement of nearconservation of properties on the large scale.

\subsection{The Standard Solution}

The resolution matrix of the Gauss-Markov estimate [e.g., Wunsch, 1996, p. 170] shows that heat and salt; anomaly conservation in the layers are well resolved, that is, provide independent information. The anomaly equations for the conservative tracer "NO" $\left(9.1 \mathrm{NO}_{3}+\mathrm{O}_{2}\right.$ [Broecker, 1974]) are, in general, indistinguishable from. the "PO" equations, and we choose to conserve "PO" because the nitrogen cycle is the more complex one. Mass conservation equations are only weakly resolved.
The solution elements (reference velocities, Ekman transport, fieshwater flux, diancutral mass transfers, and diffusivilies) were all within the a priori range.

The "Ekman" transport adjustment is shown in Table 3. The adjustment is not atitibutable solely to the Ekman transport, as it inchudes everything accommodated in the first layer(s) to meet the conservation constraints. While a major change is required at $\mathrm{T} 2 \mathrm{~W}$ in the Mozambique Channel where the baroclinic variability is large (see section 5.2 below), the Ekman transport is almost, unmodified in the other sections from the NCEP initial guess.

Except for silica, all constraints were met, within uncertainties, and the solution appears to be both dynamically and statistically acceptable. Dissolved silica in the Indian basin is conserved only at two standard deviations, with a net convergence of $-620 \pm 360 \mathrm{kmol} \mathrm{Si} \mathrm{s}^{-1}$, possibly associated with the high ITF flux (there is an equivalent divergence in the central Pacific region of the global model). (Bryden and Beal, submitted manuscript, 2000), found silica flux at, $32^{\circ} \mathrm{S}$ similar to ours.) Mass residuals in individual layers are smaller than $1 \mathrm{~Sv}$, and all are indistinguishable from zero within two standard deviations (Figure 2). The net residual in the Mozambique box (not shown) is also small at $0 \pm 7 \mathrm{~Sv}$.

The 13 and I10 intersection near Australia (Figure 1) generates a small closed box. Experience shows such boxes should not be constrained, owing to the potentially large hydrographic aliases at open-ocean intersections. Nevertheless, the residuals in this small area were confirmed, a posteriori, to be small. The reference velocities and absolute velocities from the standard solution are given in G99, and our discussion will focus on the net integrated fluxes and divergences.

5.1.1. Net fluxes. The net "overturning stream function" and the net flux across each section are shown in Figure 3. The overturning stream function corresponds to the zonally integrated mass flux integrated from the bottom, with each step giving the direction and magnitude of the flow in the layer above (positive to the north for zonal sections, and eastward for JADE). The overturning stream function has the advantage of making the useful quantities readily accessible to the eye: the sum of the fluxes over several layers being just the difference between the stream function values at the top of the top layer and at the bottom of the bottom

Table 6. Conservation Constraints for the Standard Solution $^{\text {a }}$

\begin{tabular}{lll}
\hline & Top-to-Bottom & Inclividual layers \\
\hline Mass & yes & yes \\
Heat & no & below surface \\
Salinity & yes & yes \\
Silicat & yes & no \\
"NO" $\left(9.1 \mathrm{NO}_{3}+\mathrm{O}_{2}\right)$ & no & no \\
"PO" $\left(170 \mathrm{PO}_{4}+\mathrm{O}_{2}\right)$ & no & below surface \\
\hline
\end{tabular}

"Heat, salinity, and "PO" use the anomaly formulation. 
a) Subtropical $325-20 \mathrm{~S}$

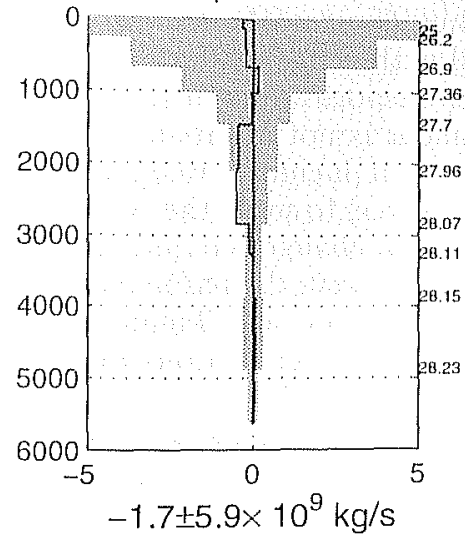

b) Tropical $20 S-8 S$

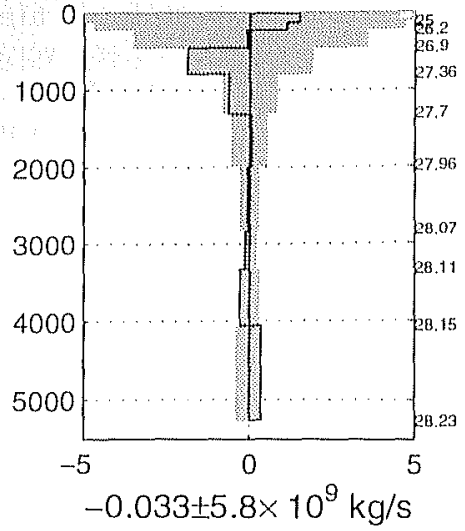

c) North (8S-JADE 89-Coast)

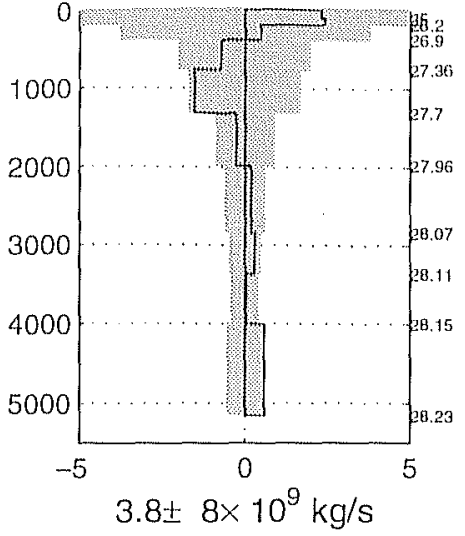

Figure 2. Standard solution mass residuals in the Indian Ocean in (a) the subtropical box; (b) the tropical box, and (c) the north Indian box, which also includes the area between 110 and JADE 89. The line gives the residual in individual layers (in $10^{9} \mathrm{~kg} \mathrm{~s}^{-1}$ ), and the shaded area gives the one standard deviation uncertainty. The top-to-bottom residual is indicated below the graph. Deptl is given in dbar.

a) 15 (32S)

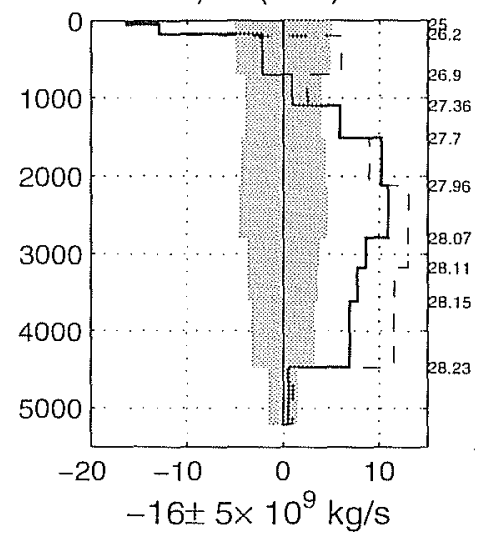

d) 14 (Mozambique S)

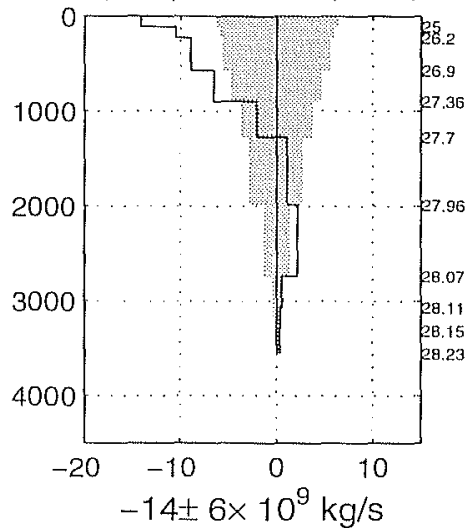

b) $13+14(20 S)$

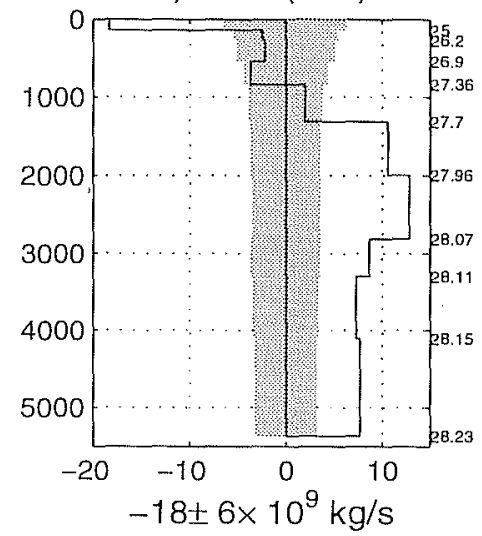

e) I2W (Mozambique N)

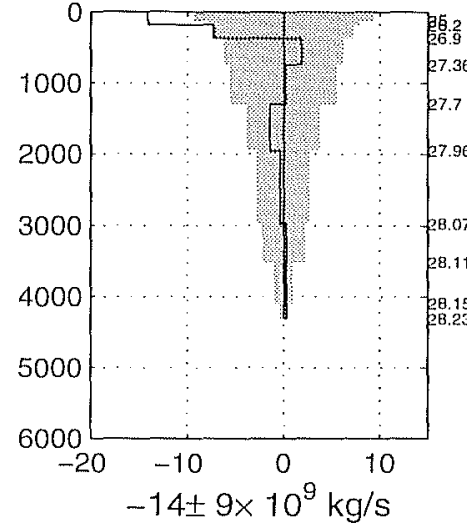

c) $12 W+12+110(8 S)$

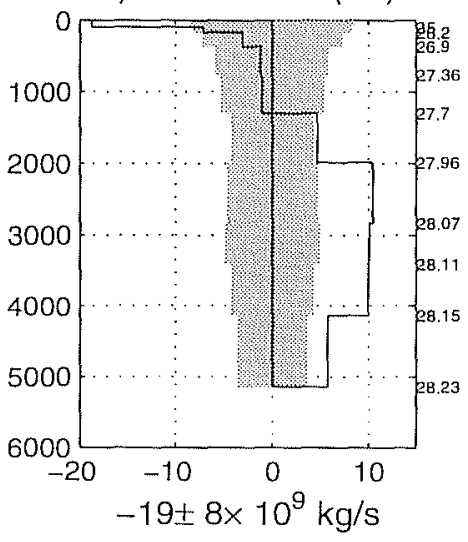

f) JADE 89 (116E)

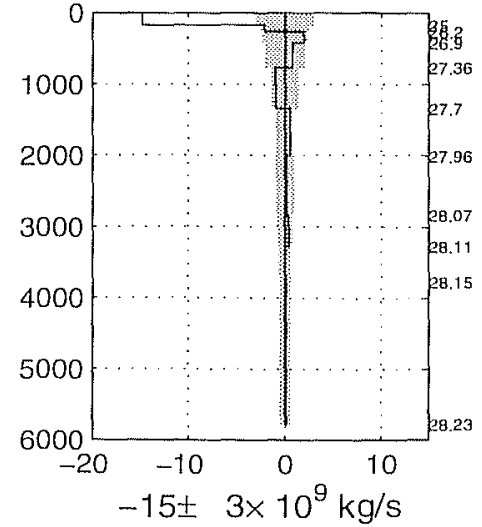

Figure 3. Overturning stream function for the standard solution across (a) $32^{\circ} \mathrm{S}$, (b) $20^{\circ} \mathrm{S}$, (c) $8^{\circ} \mathrm{S}$, (d) the southern Mozanbique Channel, (e) northern Mozambique Channel, and (f) the Indonesian Throughflow. The shaded area gives the uncertainty (plus or minus one standard deviation). The overtuming stream function corresponds to the mass flux integrated from the bottom, with each step of the stream function giving the direction and magnitude of the flow in the layer above (positive to the north/east). The net transport is indicated below each graph. The layer interfaces are indicated to the right of each graph. The Robbins and Toole [1997] (RT97) solution is indicated by the dashed line in Figure 3a. Depth is given in dbar. 
laver. The uncertainties, calculated from the error covariance of the solution vector, are given by the shaded area. The net meridional mass fluxes, which inchude the Ekman transportis, are interpreted as equal to the ITF flux and are given below each graph of Figure 3 and slsetched in Figure 4 (upper map).

These net mass flux estimaties are the same across each latitude, within error bars. At, $32^{\circ} \mathrm{S}$, the ITF flux is estimated as $16 \pm 5 \mathrm{~Sv}$ (Figure 3a). Through J89, the net flux is $15 \pm 3 \mathrm{Sr}$ westward (Figure $3 \mathrm{f}$ ), in the upper range of the a priori constraint on the ITF. (The final uncertainty of the TTF is surprisingly small, given the prior uncertainty. Its size results from the strong bathymetric constraints below the sill depth (Table 4) which were chosen to suppress the small-scale structures that; otherwise appear there. These constraints may well be artificially tight. An uncertainty of $\pm 5 \mathrm{~Sv}$ is believed to be more realistic, as discussed later.) In the Mozambique Channel the flux is southward and of the same magnitude as the ITF, $14 \pm 6 \mathrm{~Sv}$ (I4 and I2W, Figures $3 \mathrm{~d}$ and $3 e$ ), implying a weak and uncertain net transport between Madagascar and Australia of $-4 \pm 8 \mathrm{~Sv}$ (I3, not: shown). The net transport through 110 is westward, but is very uncertain, $2 \pm 14 \mathrm{~Sv}$, so that the transport between Java and the I2-I10 intersection is not deter- mined. Nevertheless, a 15 -Sv westward transport is observed on 110 north of $11.5^{\circ} \mathrm{S}$ (not shown, see G99). This flux coincides with the ITT path estimated by Gordon et al. [1997].

5.1.2. The meridional overturning circulation. The estimatied Indian Ocean overturning, or deep inflow, below $2000 \mathrm{dbar}$ at, $32^{\circ} \mathrm{S}$ is $10.6 \pm 4 \mathrm{~Sv}$ (I5, Figure $3 a$ ). Similar values are obtained at, $20^{\circ} \mathrm{S}$ (i.e., $\mathrm{I} 4 \mathrm{t}-\mathrm{T} 3$ ) and $8^{\circ} \mathrm{S}(\mathrm{T} 2 \mathrm{~W}+\mathrm{I} 2+[10)$, although the vertical structure changes due to dianeutral exchanges (described below). The net fluxes below $\gamma^{n}=27.96(\approx 2000$ dbar $)$ in each deep basin are slietched in Figure 4 (lower map). Most. numbers are uncertain (dashed arrows), reflecting the null space uncertainty, that is, the lack of resolution below the basin scale.

Although the net inflow that we find below $2000 \mathrm{dbar}$ is about the same magnitude as the one obtianed by RT97, the flow has a different horizontal and vertical structure. A detailed comparison of the northward deep water flux below 2000 dbar (layers 7 to 11) and cumulated from the west to east is given in Figure 5 (full line, upper curve). In our solution the Agulhas Undercurrent carries $13 \pm 5 \mathrm{~Sv}$ to the north in layers 6 to 7 west of $31^{\circ} \mathrm{E}$ with an immediate southward recirculation to its east, producing an insignificant transport of $3 \pm 6 \mathrm{~Sv}$
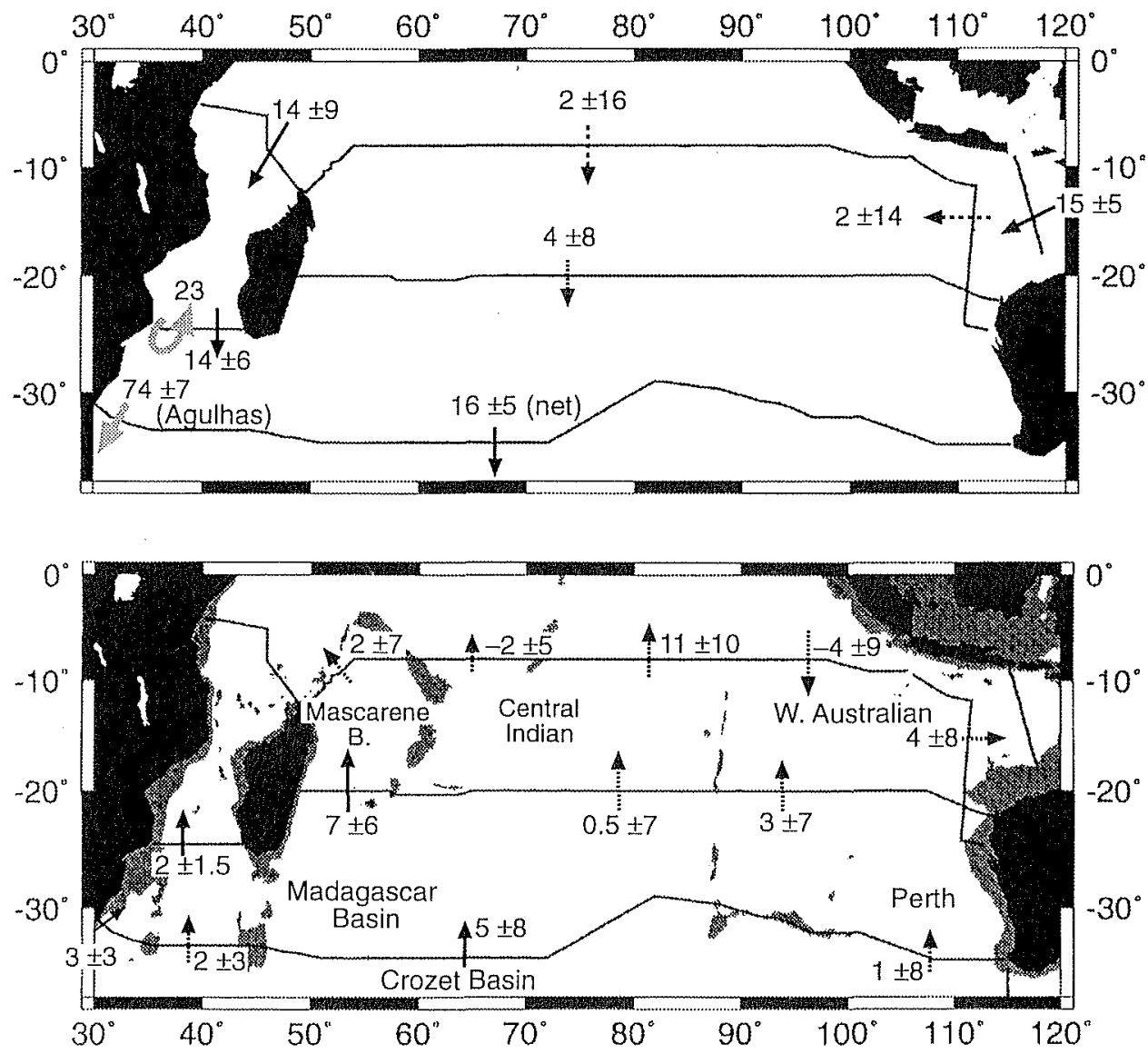

Figure 4. (top) Integrated net mass fluxes across each section are shown by thin solid arrows for the standard solution (in Sv). The Agulhas Current and the strong recirculation in the Mozambique Channel are indicated by the thick shaded arrows. (bottom) Transports in individual basins below $\gamma^{n}=27.96$ (about $2000 \mathrm{dbar}$ ). Dotted arrows indicate transports with large uncertainties. Topography that is shallower than $2000 \mathrm{dbar}$ is shaded. 


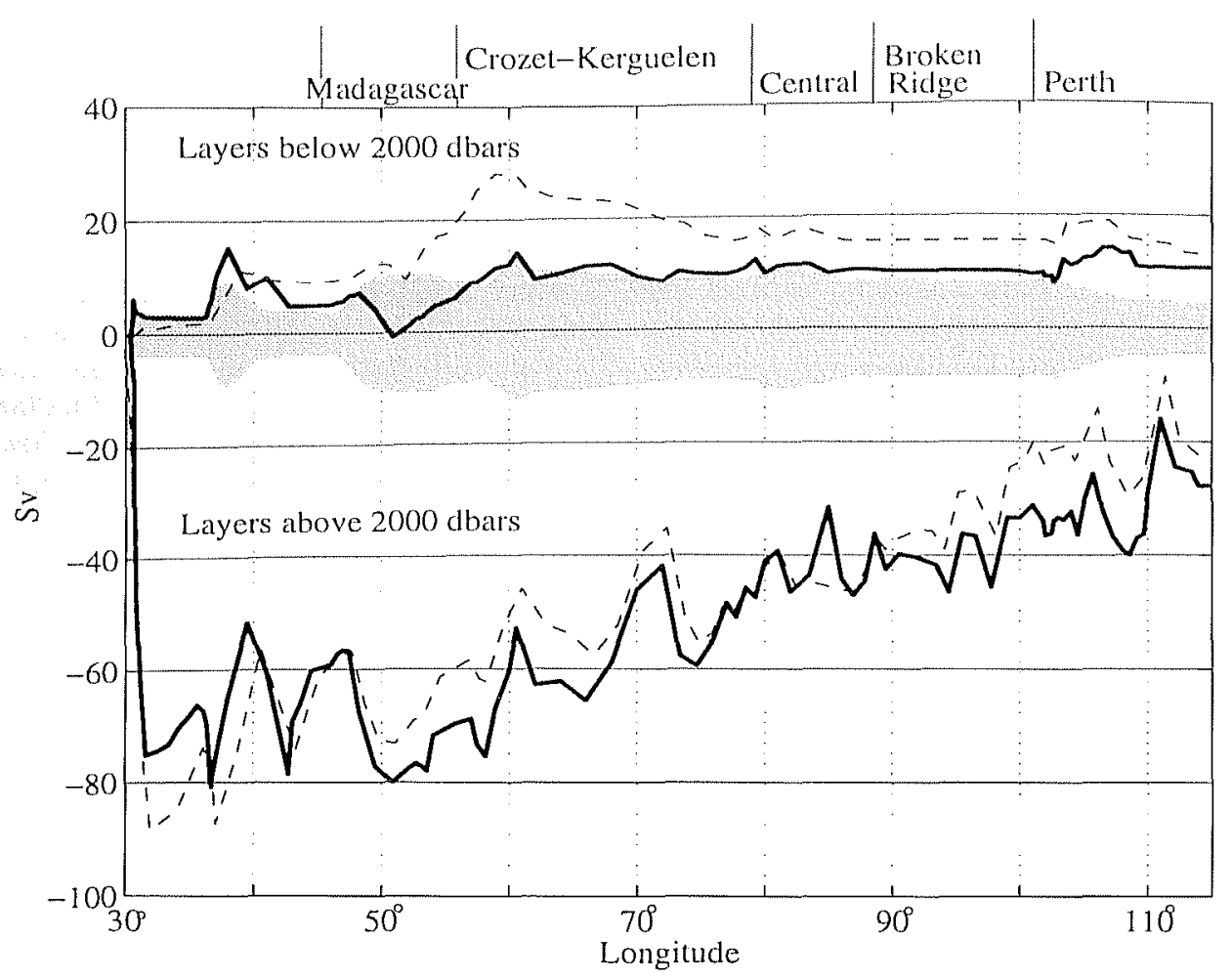

Figure 5. Meridional mass transport cumulated west to east at $32^{\circ} \mathrm{S}$, above and below $\gamma^{n}=$ 27.96 (about 2000 dbar). The solid lines give the standard solution circulation (one standard deviation for layers below 2000 dbar is shaded). For comparison, the dashed line is the RT97 silica-conserving circulation (partially adapted from RT97).

to the north between the coast of Africa and $35^{\circ} \mathrm{E}$ in those layers. This feature was not present in the previous inversions. In the Madagascar-Crozet basin and below 2000 dbar, the strength of the cyclonic circulation centered on $60^{\circ} \mathrm{E}$ found by RT97 is decreased, so that there is no southward flow east of $60^{\circ} \mathrm{E}$ in the CrozetKerguelen basin (Figure 5, upper curves). About half of the net flow below 2000 dbar occurs in these basins, in qualitative agreement with recent, current meter measurements [Haine et al., 1998]. In the Perth basin, there is a weak and uncertain cyclonic circulation, and the net flux below 2000 dbar is indistinguishable from zero $(1 \pm 8 \mathrm{~Sv}$ to the north).

The vertical structure of the deep flow differs from that of RT97 as well (dashed line, Figure 3a). Below $\gamma^{n}=28.11$, our northward flux is $8 \pm 3.5 \mathrm{~Sv}$, whereas the deep inflow in the RT97 solution below this surface was $12 \pm 3 \mathrm{~Sv}$. However, in our solution there is an additional 2.6 Sv of northward flow just above $\gamma^{n}=28.11$, so that the total deep inflow below 2000 dbar is similar to that of RT97. RT97 constrained the deep flow to move away from its sources in individual basins, resulting in an equivalent constraint on the Circumpolar Deep Water (CDW) flux of $18 \pm 5 \mathrm{~Sv}$ northward below $\gamma^{n}=28.11$ (their Table 3 , with the errors computed by assuming the constraints in the different basins are independent). The magnitudes and weights of these constraints were imposed subjectively (P. Robbins, personal communication, 1998) and account for their larger resultant inflow at depth.
At. $32^{\circ} \mathrm{S}$, but in the bottom layers alone (below $\gamma^{n}=$ $28.11,3200$ dbar to bottom, not shown), the flux indicates northward directed boundary currents along the ridges. Half of the $8 \pm 3.5 \mathrm{~Sv}$ net northward flow occurs in the Madagascar-Crozet basins while the other half occurs in the Perth basin. However, the character of the horizontal structure of the deep flow is again uncertain and depends upon the depth range considered.

At $20^{\circ} \mathrm{S}$ between Madagascar and Australia, the flux in layers below $2000 \mathrm{dbar}, 11 \pm 4 \mathrm{~Sv}$, occurs mainly in the Mascarene basin (Figure 4, $7 \pm 6 \mathrm{~Sv}$ northward, of which $4 \pm 5 \mathrm{~Sv}$ occurs west of Mauritius $\left(57^{\circ} \mathrm{E}\right)$ ). In both the central Indian and west Australian basins, the flows are noisy and uncertain, reflecting again the lack of horizontal resolution. Farther north, the fluxes in individual basins become more and more uncertain.

The total deep water inflow into the Indian Ocean, $10.6 \pm 4 \mathrm{~Sv}$, is thus consistent with the RT97 result $(12 \pm 3 \mathrm{~Sv})$, and despite the structural differences mentioned above remains larger than the GCM results. This overturning is the residual sum of strong local horizontal fluxes that partially cancel, for example, those in the Agulluas Undercurrent, a 15-Sv eddy near $39^{\circ} \mathrm{E}$, and the Madagascar-Crozet basin circulation (Figure 5).

5.1.3. Intermediate and surface flows. The cumulative flow from the west across $32^{\circ} \mathrm{S}$ and above 2000 dbar (layers 1-6) is shown in Figure 5 (lower curves). In the surface layers, at $32^{\circ} \mathrm{S}$ (15), the Agulhas Current carries $74 \pm 7 \mathrm{~Sv}$ to the south in layers 1 to 5 west of $32^{\circ} \mathrm{E}$, which is thus consistent with the Beal and Bry- 
den [1997] estimate of $69 \pm 2 \mathrm{~Sv}$. Differences with the RT97 solution are found in a few other places, but, neither solution indicates any obvious horizontal recirculation; the northward wind-driven flow in the gyre occurs over the whole interion.

At $25^{\circ} \mathrm{S}$ in the Mozambique Channel, a strong anticyclonic circulation results in a powerful southward curent of $23 \pm 3 \mathrm{~Sv}$ at the westem bounday in layers 1 to 5 between $36^{\circ} \mathrm{E}$ and $37^{\circ} \mathrm{E}$ (indicated in Figued, upper map).

5.1.4. Summary of the standard circulation. The standard circulation is thus associated with an Agulhas Cument of $74 \pm 7 \mathrm{~Sv}$ and with a relatively strong ITF of $15 \pm 5 \mathrm{~Sv}$. The overturning rate that we obtain, $10.6 \pm 4 \mathrm{~Sv}$, is similar to the Robbins and Toole [1997] and Bryden and Beal (submitted manuscript, 2000) estimates. It is significantily larger than the Fu[1986] estimate (3.6 Sv) and smaller than, but consistent with, the estimate of Macdonald [1998] (17 $\pm 5 \mathrm{~Sv}$ ).

A much weaker inflow is found consistently in GCM simulations [Zhang and Marotzke, 1999]. However, general circulation models have their limitations (weak vertical mixing, dependence upon climatological forcing; and low resolution of the deep boundary currents), and so their systematic error could easily explain their less vigorous overturning. Nevertheless, to test the hypothesis of small cleep inflow, an experiment, was tried constaining the flow below $2000 \mathrm{dbar}$ as $0 \pm 2 \mathrm{~Sv}$. The model produced a $2 \pm 2 \mathrm{~Sv}$ northward flow below 2000 dbar by returning part of its $4 \pm 3 \mathrm{~Sv}$ northward bottom inflow between 2500 and $3500 \mathrm{dbar}$, but the shallow meridional overtuming of Lee and Marotzke [1997, 1998] was not found. There was no major violation in the conservation equations in the Inclian Ocean. Dianeutral transfers were, however, found to be significantly different from zero and oriented downward in the subtropicai and tropical regions. Downward fluxes are associated with negative diffusivities, and consequently this solution was rejected as unlikely to be physically acceptable.

\subsection{The Mozambique Channel}

Obtaining a time average circulation in the Mozambique Channel is a challenge because the I4 and I2W sections were taken at different, seasons and the $\mathrm{I} 2 \mathrm{~W}$ section is close to the equator $\left(4^{\circ} \mathrm{S}\right)$, enhancing the noise in the geost, ophic balance. Initial inversions produced a large and significant convergence in the intermediate and sufface layers of the Mozambique Channel box. This convergence was found to be insensitive to the reference surface: The model adjusted the reference velocities to produce the same integrated flow for an initial sill deptil reference (2500 dbar) and an initial bottom reference. Because the convergence was significant, the original model was rejected. The error budget that we adapted from the Atlantic (G99) is too optimistic for this seasonally variable region. One could increase the a priori noise to account for the large variability in this region. The alternative that we adopted was to allow a large ageostrophic adjustment in the first layer of I2W to accommodate the variability. This adjustment formally appears as the "Ekman" transport adjustment, Table 3 .
After adjustment, mass is balanced within 1 Sv in in dividual layers (not shown). Because of the high variability, the vertical stacture of the flow in the first layers is probably moalistic. Nevertheless, tho $14 \pm 65 \mathrm{~V}$ net flux through the channel (Figures $3 \mathrm{~d}$ and 30 ) is relatively robust and consistent within error bars with the different experiments that have been done in this region. DiMarco et al. [1998] obtained a bit larger southward transport (18 to $21 \mathrm{~Sv}$ ) assuming a zero velocity at the sill depth and below. However, the relative transport below 2500 dbar was not included in their calculation (S. F. DiMarco, personal communication, 1998). To satisfy the no flow condition below sill depth on $12 \mathrm{~W}$, important reference velocity adjustments were required, causing the smaller transport that: we report.

\subsection{The Pacific Indian Throughflow (ITF)}

The mass fux through the ITF $(15 \pm 3 \mathrm{~Sv})$ is on the high side of the commonly accepted values [e.g., Meyers ef al., 1995; Godfrey, 1996], but; consistent with the preferred Ficut et al. [1994] value from the same JADE data and with recent direct measurements in the Malkassar Strait (Gordon et al. [1999, Figure 2b] suggested a value of $12.5 \mathrm{~Sv}$ for a null ENSO index).

The silica flux through the JADE section is larger by a factor of $2\left(400 \pm 200 \mathrm{kmol} \mathrm{Si} \mathrm{s}^{-1}\right)$ than what was estimated by RT97 from climatiology. The section was constructed by adding a station from the 1992 JADE, section to the 1989.JADE data to close the box at the northern end. Such an addition is artificial and may introduce a bias because of the large seasonal variability in the Java Current. Indeed, Fieux et al. [1994] found very different ITF transports in 1989 and 1992, subject to the large uncertainty in their calculation from internal wave noise [Fieux et al., 1994; G99]. However, without this additional station the model produced large silica fluxes below the ITF sill depth, resulting in a net eastward silica flux through the section. Adding this station did not change the net mass flux after adjustment, but permitted it to formally include property fluxes between the last 1989 station and the coast. A large a priori uncertainty and reference velocity adjustment were allowed at the added pair so that it has litile influence on the results. Rather, it is used by the model as a buffer to satisfy the conservation equations on a large scale.

The ITF (Figure 3f) shows a weak net mass flux of intermediate waters flowing eastward (3Sv, layers $3-4$, 300 to 800 dbar), marginally distinguishable from zero in those layers. Tracer properties in the Indian Ocean exhibit; a tongue of silica emanating westward from Indonesian waters at these depths [Wyrthi, 1970]. Fieun et al. [1994] discussed this eastward intermediate flux from those same 1989 data and found no inconsistency with the local water properties, the net flux being the sum of large and opposite fluxes of different water types. As already noted above, large-scale property tongues do not necessarily imply net mass flux. Any zero-mean timedependent, mass flux between the Pacific and the Indian Oceans which leaves behind fluid particles on the return flow would generate such a tongue [see Wunsch, 1996, p. 79]. 
This intermediate water flux is enhanced when one removes the $1992 \mathrm{JADE}$ station near Bali, and forcing the net intermediate silica flux to be westward causes large eastward silica and mass fluxes below sill depth On the JADE section, an unrealistic circulation. It was thus decided to leave this intermediate silica flux unconstrained.

The local formal uncertainty of $\pm 3 \mathrm{~Sv}$ on the ITF discussed above may be optimistic, its small value arising from the tight topographic constraints. A more realistic ITF uncertainty is probably the net mass flux uncertiainty at $32^{\circ} \mathrm{S}$ of $\pm 5 \mathrm{~Sv}$.

\subsection{Dianeutral Transfers and Mixing}

Dianeutral mass transfers (Figures 6a-6c) indicate downwelling at the base of the surface layers of the subtropical and north Indian boxes. Most of the deep upwelling appears to take place in the north Indian box, with about $10 \pm 5 \mathrm{~Sv}\left(3 \pm 1.5 \times 10^{-5} \mathrm{~cm} \mathrm{~s}^{-1}\right)$. The deep dianeutral transfers in the subtropical and tropical boxes are not significantly different from zero. Upwelling in the north is associated with net dianeutral mixing equivalent to diffusivity values of 4 to $10 \mathrm{~cm}^{2} \mathrm{~s}^{-1}$ with larger values in the deepest, layer approaching $30 \mathrm{~cm}^{2} \mathrm{~s}^{-1}$. (Owing to possible large errors in the horizontal area of neutral surfaces at depths, this latter value is uncertann.) In this box, down-gradient mixing is found consistently over all the deep interfaces, although there was no requirement, that the mixing coefficient, be positive. The average diffusivity at interfaces below layer 5 and above the last interface is $8.6 \pm 4 \mathrm{~cm}^{2} \mathrm{~s}^{-1}$ in the nonth Indian box. This value is much larger than the $1 \mathrm{~cm}^{2} \mathrm{~s}^{-1}$ global mixing required by a global one-dimensional balance [Munk and Wunsch, 1998], bul, it derives from a more accurate tracer budget and includes all processes, such as boundary effects. Indeed, the north Indian Ocean topography is relatively rough, which can lead to enhanced mixing, as supported by microstructure measurements [e.g., Polzin et al., 1997]. (In the Mozambique Channel, dianeutral exchanges are not significant, owing to the large seasonal baroclinic variability there.)

\section{Selected Sensitivity Experiments}

A number of experiments were performed with the full property equations (that is, with salt, heat, and PO not witten as anomalies). Use of full property equations has several drawbacks: The system is of lower rank, and it is difficult to weight the heat conservation equation properly. An uncertiainty of $\pm 0.1 \mathrm{PW}$ in the heat equation is plausible in the thermocline; it is an a) Subtropical $32 \mathrm{~S}-20 \mathrm{~S}$

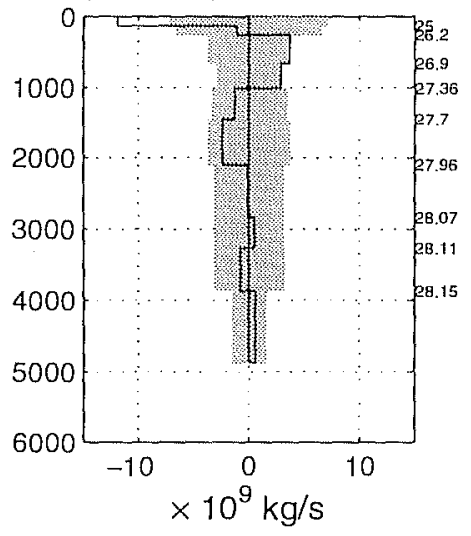

$\kappa_{z}$

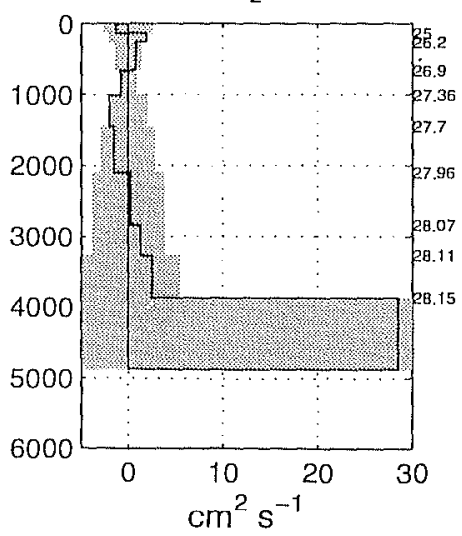

b) Tropical $20 S-8 S$
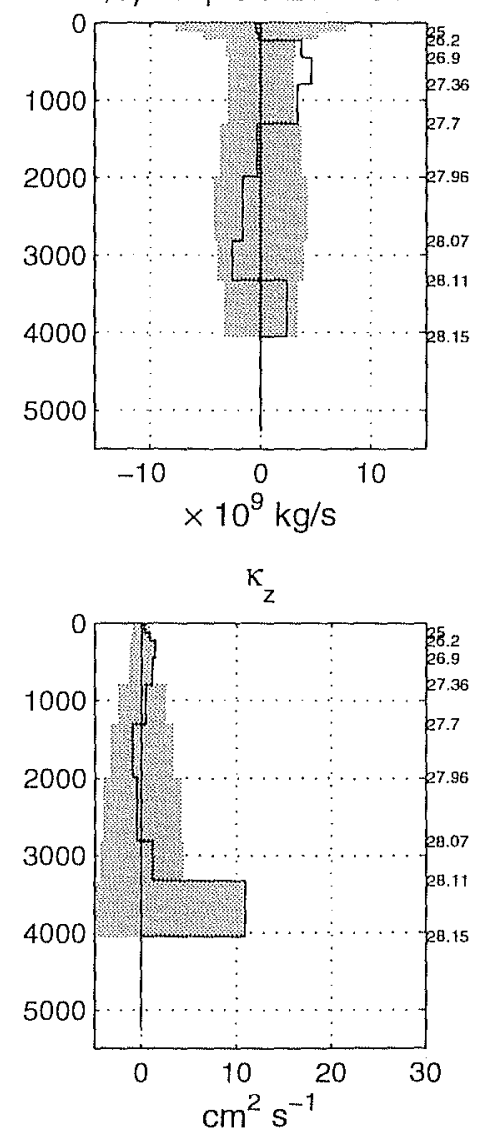

c) North (8S-JADE 89-Coast)

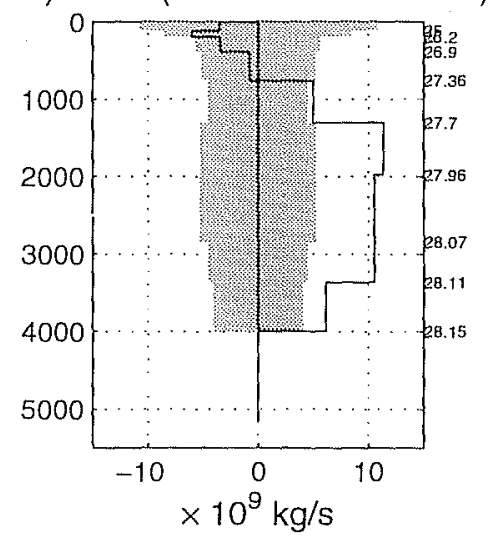

$\kappa_{z}$

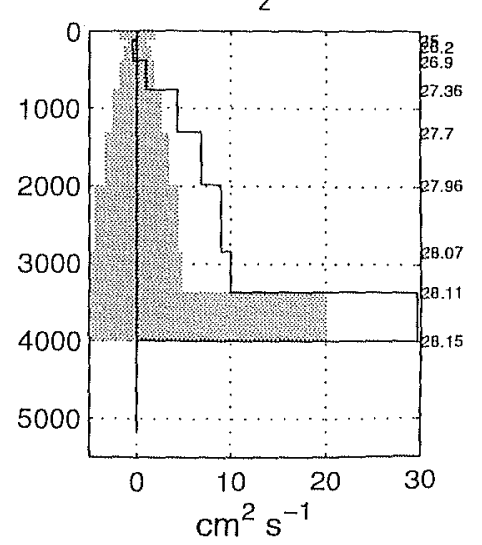

Figure 6. Standard solution dianeutral mass transfers (upper graphs) and diffusivities (lower graphs) for the (a) subtropical, (b) tropical, and (c) north regions in the Indian Ocean. The line indicates the transfer or diffusivity at the bottom of the layer. The shaded area denotes the uncertainty (plus or minus one standard deviation). Depth is given in dbar. 
a) Subtropical $32 \mathrm{~S}-20 \mathrm{~S}$

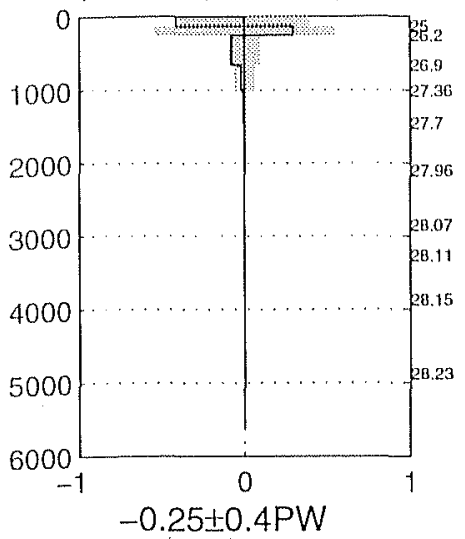

b) Tropical 20S-8S

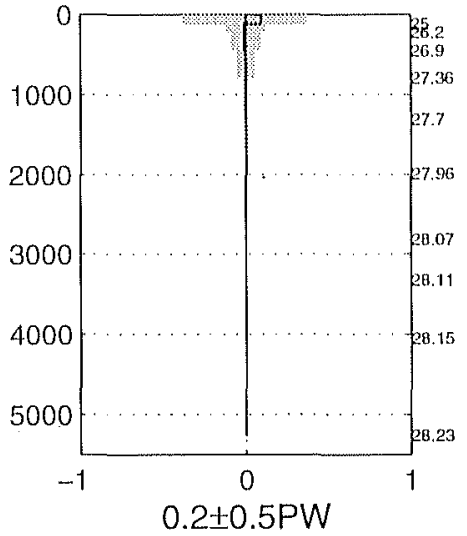

c) North (8S-JADE 89-Coast)

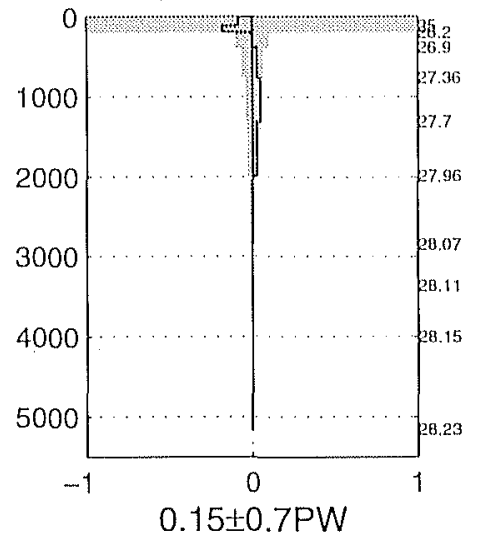

Figure 7. Standard solution heat anomaly residuals in (a) the subtropical box, (b) the tropical box, and (c) the north Indian box. Positive numbers indicate oceanic heat gain. The shaded area denotes the one standard deviation uncertainty.

overestimate in the deep layers characterized by smaller temperature gradients. In the anomaly equation formulation, the uncertainty can be attitibuted more consistently (Section A.3), but the solution is, as always, directly dependent upon the reliability of the estimated error structure of the equations.

The solution with the full property equations (not; shown) indicates a similar deep water inflow at $32^{\circ} \mathrm{S}$ but with increased transport 15-18Sv as one goes north. For the practical reason mentioned above, heat conservation was not required. To balance mass, the model creates downward dianeutral fluxes in the subtropical and tropical boxes, with a larger upwelling occurring in the north Indian box. Several experiments showed that with the full property equations, the model could not produce a consistent circulation without those downward dianeutral fluxes. Although the circulations were not statistically different from the standard solution, those solutions were discarded.

An experiment with anomaly equations (including heat) but no PO constraints indicated a similar circulation with downward fluxes in the subtropical and tropical boxes.

\section{Heat and Freshwater Budget}

In the standard solution the southward energy flux across the three zonal sections are $1.5 \pm 0.2 \mathrm{PW}\left(32^{\circ} \mathrm{S}\right)$, $1.8 \pm 0.4 \mathrm{PW}\left(20^{\circ} \mathrm{S}\right)$, and $1.6 \pm 0.8 \mathrm{PW}\left(8^{\circ} \mathrm{S}\right)$. Energy transports across each section are expressed in units of petawatts referred to the Celsius scale for unit consistency with most of the literature. Warren [1999] argued, convincingly, that the terminology "heat flux" is inappropriate in this context (see also Bohren, and Albrecht [1998, pp. 24-28]) and one should refer to the "energy flux". This flux is, however, not that of the total energy: It does not include the kinetic energy (a small contribution here), and the usage "heat flux" is now so deeply embedded in the literature that we continue to use the terms interchangeably until some consensus has emerged as to the best label.

As a consequence of the large inflow of warm water from the ITF $(1.36 \pm 0.15 \mathrm{PW}$ heat transport across
JADE), the net estimated heat gain over the Indian Ocean is indistinguishable from zero $(0.1 \pm 0.2 \mathrm{PW})$. The heat residual anomalies in individual boxes (Figure 7) are also not significantly different from zero. Only in the subtropical box (Figure 7a) is there a marginal indication of oceanic heat loss in the surface layer $(0.5 \pm$ $0.4 \mathrm{PW})$ and heat gain in the second layer $(0.4 \pm 0.6 \mathrm{PW})$, which outcrops almost completely by $32^{\circ} \mathrm{S}$.

Neither of the European Centre for Medium-Range Weather Forecasts (ECMWF) heat flux estimates of Siefridt et al. [1999] and E. Garnier et al. (Air-sea fluxes from 15 years of ECMWF reanalysis: A surface boundary condition for OGCMs?, submitted to International Journal of Climatology, 2000; hereafter Garnier et al., submitted manuscript, 2000) shows significant heating over the northern part of the Indian basin; nor does the NCEP/National Center for Atmospheric Research (NCAR) reanalysis of Kalnay et al. [1996], (displayed by Garnier et al., submitted manuscript, 2000). However, all indicate a cooling of $0.4 \mathrm{PW}$ between $20^{\circ} \mathrm{S}$ and $32^{\circ} \mathrm{S}$.

On the other hand, the Comprehensive Ocean Atmosphere Data Set (COADS) data of da Silva et al. [1996] and the climatologies of Oberhuber [1988] and Hsiung [1985] indicate a warming of about $1.2 \mathrm{PW}$ in the Indian Ocean north of $20^{\circ} \mathrm{S}$. The GCM assimilation computations of Lee and Marotzke [1997, 1998] (hereafter LM97,98) which are forced with the Oberhuber [1988] climatology, indicate a consistent heating between $20^{\circ} \mathrm{N}$ and $14^{\circ} \mathrm{S}(0.8 \mathrm{PW})$ and a cooling in the subtropical region $\left(14^{\circ} \mathrm{S}-32^{\circ} \mathrm{S}, 0.3 \mathrm{PW}\right)$. Several other GCM studies based on different surface forcings show heating magnitudes north of $14^{\circ} \mathrm{S}$ that are similar to those of LM97,98 (i.e., Figure 19 of the latter). All GCM-based inversions have a, relatively weak or nonexistent ITF, so that local a.tmospheric heating accounts for most of the temperature flux leaving the basin at $32^{\circ} \mathrm{S}$.

The estimate of heat flux divergence over the Indian Ocean is thus largely determined by the size of the ITF [e.g., Godfrey, 1996]. Based on an ITF varying randomly from 1 to $11 \mathrm{~Sv}$, RT97 estimated the heat flux divergence for the Indian Ocean north of $32^{\circ} \mathrm{S}$ as $0.4 \pm 0.2 \mathrm{PW}$, similar to the result of Hastenrath 
and Greischar [1993] that was based on a climatological combination of ship observation, radiation measurements, and stibsurface temperature. Bryden and Beal (subrnitted manuscript, 2000) suggested a heat flux divergence of order 0.66 PW over the Indian Basin, also subject to the ITF uncertainty.

Our comparatively lower heat gain over the Indian basin resilts from the relatively large ITF heat flux combined with a relatively weak overturning circulation. Similarly, the heat transport in the South Pacific part of the global model is oriented northward because of the large ITF (G99).

Freshwater divergences are calculated as part of the solution through the anomaly formulation. Infered precipitation plus runoff minus evaporation (P-E) freshwater divergences are indistinguishable from zero in the north Indian Ocean sector, north of $8^{\circ} \mathrm{S}$ (I2-I10, $0.1 \pm 0.3 \mathrm{~Sv}$ net precipitation). South of $8^{\circ} \mathrm{S}$, the solution shows net evaporation in the tropical $\left(20^{\circ} \mathrm{S}-8^{\circ} \mathrm{S}\right)$ and subtropical boxes ( $\left.32^{\circ} \mathrm{S}-20^{\circ} \mathrm{S}\right)$ (Table 7 , a minus sign denotes net evaporation).

These two latter estimates are consistent with the estimates from satellite radiometric data of Jourdan et al. [1997], (Table 7, their error bars are not given for these latitude bands, but they probably do not exceed 100\%). Wijffels et al. [1992], Macdonald [1995], and Oberhuber [1988] reported estimates in the same range. (Note that the Wijffels et al. [1992] estimate is essentially an integration of the Buumgartner and Reichel [1975] estimate.) Oberhuber's [1988] values have a. greater contrast, north and south of $10^{\circ} \mathrm{S}$, but are within our error bars. Overall, the Indian Ocean is evaporative, with $-0.6 \pm 0.4 \mathrm{Sr}$ net, air-sea exchange. As for all property fluxes, the model's large Indonesian Throughflow may affect substantially the estimated freshwater divergences over the Indian Ocean, but we find no inconsistency with previous independent, estimates.

\section{Summary and Conclusions}

A global hydrographic inverse model is used to determine the large-scale circulation in the Indian Ocean. The circulation estimate is based on zonal sections in the Indian Ocean at $32^{\circ} \mathrm{S}, 20^{\circ} \mathrm{S}$, and $8^{\circ} \mathrm{S}$ and two (in- complete) mericlional sections between Australia and Indonesia at $110^{\circ} \mathrm{E}$ and $116^{\circ} \mathrm{E}$. Mass, sall, heat, "PO", and silica are conserved. Dianeutival advective and diffusive property fluxes are lesolved through the use of anomaly equations.

Figure 3 shows our best estimale of the net meridional (a function of depth and latitude) overtuning stream function of the Indian Ocean as determined from the WOCE hydrographic sections both locally and globally. This estimate is consistent with both dynamics and simple biogeochemical principles (silica and "PO" conservation). Deep upwelling is retuned in the 8001.500 dbar depth range, rather than near-surface. Residwals of nitrate, phosphate, and oxygen were also examined (G99), but the uncertainties are large.

1. A meridional overturning strength (measured by the rate of deep inflow) of $11 \pm 4 \mathrm{~Sv}$ at all three latitudes $\left(32^{\circ} \mathrm{S}, 20^{\circ} \mathrm{S}\right.$, and $\left.8^{\circ} \mathrm{S}\right)$ is consistently obtitined, compatible with the RT97 estimate at $32^{\circ} \mathrm{S}$. Nevertheless, the global circulation requires modifications in the zonal and vertical partilion of the deep flow found by RT97. Results from general circulation models have consistently found a weaker deep inflow [Zhang and Marotzke, 1999] which is barely compatible, within an uncertainty of two standard cleviations, with our results. The deep inflow was found to be insensitive to most of our model parameters (e.g., an inversion starting with a bottom reference for all sections in the Indian Ocean produced no significant change in the overturning).

2. Our estimate of the average Indonesian Throughflow during the WOCE period (early 1990s) is $15 \pm 5 \mathrm{~Sv}$ westward. The result is consistent with the global circulation and recent clirect measurements in the Makassar Strait [Gordon et al., 1999], but we believe it is largely dictated by the use of the 1989 JADE cruise. The southward flux in the Mozambique Channel is of the same magnitude, implying a weak or null net flow between Madagascar and Australia.

3. Consistent upwelling and down-gradient dianeutral mixing are found in the northern part of the Indian Ocean below the surface layers, with insignificant dianeutral transfers south of about $8^{\circ} \mathrm{S}$. The deduced "equivalent, horizontal average" diffusivity ranges between 2 and $10 \mathrm{~cm}^{2} \mathrm{~s}^{-1}$ while the upwelling velocity

Table 7. Precipitation (Positive) Minus Evaporation (Negative) Estimates for the Different Oceanic Regions Bounded by the Model Sections in the Indian Ocean ${ }^{a}$

\begin{tabular}{|c|c|c|c|}
\hline & Subtropical ${ }^{\mathrm{b}}$ & Tropical $^{\mathrm{c}}$ & North Indiand $^{\mathrm{d}}$ \\
\hline $\begin{array}{l}\text { Present study } \\
\text { Jourdan et al. }[1997] \\
\text { Wijffels et al. }[1992] \\
\text { Macdonald }[1995] \\
\text { Oberhuber [1988] }\end{array}$ & $\begin{array}{l}-0.35 \pm 0.25 \\
-0.3 \\
-0.2 \\
-0.4\end{array}$ & $\begin{array}{l}-0.3 \pm 0.2 \\
-0.5 \\
-0.45\end{array}$ & $+0.1 \pm 0.3$ \\
\hline
\end{tabular}

\footnotetext{
"Units are sverdrups.

bTatitudes between $32^{\circ} \mathrm{S}$ and $20^{\circ} \mathrm{S}$.

cLatititudes between $20^{\circ} \mathrm{S}$ and $8^{\circ} \mathrm{S}$.

"Latitudes between $8^{\circ} \mathrm{S}$ and the coast.

'Average for subtropical and tropical regions.
} 
ranges between 1 and $3 \times 10^{-b} \mathrm{cms}^{-1}$, that is, in the higher end of the published range.

4. Because of the large temperature transport through the ITF, we find no significant heat gain over the northern Indian Ocean north of $8^{\circ} \mathrm{S}$, and an insignificant heat gain of $0.1 \pm 0.2 \mathrm{PW}$ over the whole basin north of $32^{\circ} \mathrm{S}$. This heat budget is consistent, with some of the existing climatologies, but; inconsistent, with others. The net evaporation fiom the Indian Ocean between $32^{\circ} \mathrm{S}$ and $8^{\circ} \mathrm{S}$ is estimated to be $0.6 \pm 0.4 \mathrm{Sr}$ and is compatible with radiometric datia [Jourdon et al., 1998].

The circulation estimate is at best an average over the period 1987-1995. The uncertainties presented here account for the errors from both the model limitations and the measurements. In particular, the alias errors resulting from non-synopticity of the sections and oceanic variability are taken into account from experiments with a GCM simulation, although it is still possible that we underestimate the monsoonal variability in the density field (section 3). Because our a priori errors are larger than in previous calculations, the present model would produce, for instance, an uncertainty of $\pm 8 \mathrm{~S} v$ with total mass and silica conservation alone [cf. Robbins and Toole, 1997]. Addition of the other sections and constraints (heat, layers, etc.) accounts for the reduced uncertainty.

The parameterization of dianeutral exchanges as single diffusion and advection coefficients over large oceanic areas may be unrealistic too. In particular, the possibility of double diffusion [e.g., You, 1999] was not 'addressed, and use of a different coefficient of heat and tracer transfers may be used in future versions of the model.

The present circulation estimate will be refined with time as it benefits from suggestions for improvement on the different parameter choices such as the initial reference surface based on new current meter measurements, floats, and altimetric data, as well as water mass analysis where the signals are important, such as in the boundary current, regions. Nevertheless, our sensitivity experiment suggested that large-scale mass transports are relatively insensitive to such changes, and substantial improvement will occur only with a data set permitting one to estimate the true time average property fluxes. In particular, the property fluxes from the $\mathrm{Pa}$ cific (ITF) are a major source of uncertainty owing to the sparsity of measurements and the large seasonality and interannual variability there.

\section{Appendix A: A Priori Uncertainties}

Uncertainties in the mass balance for layers were derived through an extensive error budget stindy (G99) taking into account, errors from both the nature of the inverse model (estimation of time average versus oceanic variability) and the measurement, noise (intelnal waves, bottom triangle, ageostrophy, and instrument noise).

\section{A.1. Baroclinic variability}

The a priori uncertainties on the flux through a single zonal section are summarized in Table Al. Errors, including the component due to the variability in the density field, were estimated for the Atlantic using a GCM [Semtner and Chervin, 1992; Stammer et al., 1996; Jayne, 1999] and extended to the Indian Ocean.

\section{A.2. Silica Conservation Weights}

The top-to-bottom silica conservation weight was based on a GCM simulation at $36^{\circ} \mathrm{N}$ in the Atlantic. (An empirical silica-temperature-salinity relation was applied to the Semtner and Chervin [1992] model output to reconstruct, a time-dependent, silica field (G99).) The uncertiainty from variability in the baroclinic field alone was estimated as $n_{S i}^{36^{\circ} N}= \pm 70 \mathrm{kmol} \mathrm{Si} \mathrm{s}^{-1}$ at $36^{\circ} \mathrm{N}$ in the Atlantic. This value was then extrapolated to other oceans. Because the average concentration of silica varies substantially with location, this uncertainty was scaled by the local average silica concentration and by the local mass variability from Table A1 (the anomaly formulation was not used for silica for technical reasons $(\mathrm{G} 99$, p. 24)):

$$
n_{S i}^{\text {local }}=n_{S^{\prime}}^{36^{\circ} N} \times \frac{\left\langle S i^{\text {local }}\right\rangle}{\left\langle S i^{36^{\circ} N}\right\rangle} \times \frac{n_{\text {Mass }}^{\text {local }}}{n_{M a s s}^{36^{\circ} N}}
$$

where $n$ is the a priori uncertainty and $\langle S i\rangle$ is the average concentration. Equation (A1) gives an a priori noise estimate $n_{S i}^{\text {local }}= \pm 700 \mathrm{kmol} \mathrm{Si} \mathrm{s}^{-1}$ for the net silica conservation in the Indian Ocean between JADE

Table A1. A Priori Uncertainty in the Mass Conservation Equation for a Single Section ${ }^{2}$

\begin{tabular}{|c|c|c|c|c|c|}
\hline \multirow[b]{2}{*}{$\begin{array}{l}\text { Latitudes } \\
{ }^{\circ} \mathrm{S}\end{array}$} & \multicolumn{2}{|c|}{ Total Flux } & \multicolumn{3}{|c|}{ Variability of Individual Layers } \\
\hline & $\begin{array}{c}\text { Measurement } \\
\text { Noise }^{b}\end{array}$ & Variability & 0-1000 dbar: & $1000-2000 \mathrm{dbar}$ & 2000 dbar to Bottom \\
\hline 30 & 3 & 6 & 2 & 1 & 0.5 \\
\hline 20 & 5 & 7 & 3 & 2 & 1. \\
\hline 10 & 10 & 10 & 7 & 3 & 2 \\
\hline 5 & 20 & 20 & 13 & 7 & 3 \\
\hline
\end{tabular}

\footnotetext{
"The results from the North Atantic part of the GCM are extrapolated at latitudes lower than $20^{\circ} \mathrm{S}$ and to the Indian Ocean regions. Values are in sverdrups and represent root-mean-square quantities.

bMeasurement noise comes from internal wave activity.
} 
and $32^{\circ} \mathrm{S}$. Net sources and sinks from burial and river runoff are much smaller [e.g., DeMaster, 1981]. Because siliceous particles are believed to have a relatively high sinking rate, the biological cycle is expected to occul: primarily in the vertical, and top-to-bottom conservation equations are expected to be independent of the biology.

\section{A.3. Anomaly Equations}

The noise in the mass conservation equations tends l,o dominate most tracer conservation equations. As a result, models expressed in terms of full property equations do not resolve the different, equations, resulting in a lower rank matrix [e.g., McDougall, 1991; Wijffels, 1993]. To better condition the system, one can subtract the mass divergence times the average property concentration for each layer from each tracer conservation equation. As discussed by Wunsch [1996, p. 272], the main issue, when using anomaly equations, is the determination of the degree of cancellation in the residual noise after subtraction.

We now estimate this degree of cancellation, or equivalently the size of the noise term in anomaly equations. The salt equation is taken for illustration. For a single zonal hydrographic section, and within a layer, the net transports of mass and salt are written (density is assumed constant to first order and omitted)

$$
\begin{aligned}
T_{M} & =\iint d x d z\left(v(x, z)+n_{v}(x, z)\right), \\
T_{S} & =\iint d x d z\left(v(x, z) S(x, z)+n_{v s}(x, z)\right),
\end{aligned}
$$

where $v(x, z)$ is the meridional velocity, the noise $n_{v}(x, z)$ and $n_{v s}(x, z)$ refer to noise in the velocity and salt advection at individual station pairs, $x$ is longitude, and $z$ is the vertical coordinate. Let $\bar{S}$ be the mean salinity of the layer and $S^{\prime} \doteq S-\bar{S}$ the salinity anomaly; then by subtracting $\bar{S}$ times (A2) from (A3), one obtains the anomaly transport for salinity:

$$
\begin{aligned}
T_{S^{\prime}} & =\iint v(x, z) S^{\prime}(x, z) d x d z+\mathbf{n}_{S}^{\prime}, \\
\text { with } \quad \mathbf{n}_{S}^{\prime} & \doteq \iint\left(n_{v s}(x, z)-\bar{S} n_{v}(x, z)\right) d x d z .(
\end{aligned}
$$

A mass transport (or mass divergence if summed over a. box) $\mathbf{n}_{M}$ is anticipated to produce a salt transport $\mathbf{n}_{S}$ of roughly $\bar{S} \mathbf{n}_{M}$ such that $\mathbf{n}_{S}^{\prime}$ should be much smaller than $\mathrm{n}_{s}$. We now formalize this statement. Assuming that the noise in the salt flux $n_{v s}(x, z)$ is mainly due to noise in the mass flux $n_{v}(x, z)$ (as opposed to being mainly caused by variations in the salinity itself), $n_{v s}(a, z)$ may be written as

$$
\begin{aligned}
n_{v s}(x, z) & =n_{v}(x, z) \times S(x, z), \\
n_{v s}(x, z) & =n_{v}(x, z) \times\left(\bar{S}+S^{\prime}(x, z)\right), \\
\text { ol } \quad \mathbf{n}_{S}^{\prime} & =\iint n_{v}(x, z) S^{\prime}(x, z) d x d z .
\end{aligned}
$$

Now, $\mathbf{n}_{S}^{\prime}$ may be divided into a component owing to the zonal average mass transport over the layer and a deviation that we call the horizontal eddy component:

$$
\begin{aligned}
\mathbf{n}_{S^{\prime}} & =\mathbf{n}_{M} \iint S^{\prime}(x, z) d x d z \\
& +\iint\left(n_{v}(x, z)-\mathbf{n}_{M}\right) S^{\prime} d x d z, \\
\mathbf{n}_{M} & \doteq \iint n_{v}(x, z) d x d z .
\end{aligned}
$$

Here, $\mathbf{n}_{M}$ is the noise in the zonally integrated mass flux over a layer from Table A $1 . \bar{S}$ is taken over a whole layer, including several sections, so that the first term of (A9) (the zonal average) is in general nonzero. As an approximate estimate for the variance of the zonal avelage component, we chose to use $\left\langle\mathrm{n}_{M}^{2}\right\rangle\left\langle\Delta S^{2}\right\rangle$, where $\triangle S$ is the a priori size of salinity variations within a layer. The size of the horizontal eddy component is unknown a priori and is assumed to be of the same magnitude or smaller than the zonal avesage component, with possible correlation between the two. This speculative assumption is supported by studies of the heat flux variability (salt was used as an example, but similar anomaly equations are written for other tracels, including heat). Jayne [1999] found that at all latitudes, variations in the baroclinic heat transport (which appears as a noise, $n_{\theta}$, in the heat equations) are about twice as large as variations in the horizontal eddy contribution to the heat, transport. Instantaneously, salinity anomaly transports display a similar behavior as heat anomaly transport [e.g., Wunsch, 1996, Figure 4-15] so that the noise in the salinity anomaly may be reasonably assumed similar.

The ad hoc, a priori, noise in the tracer anomaly equations for any tracer $C$ is thus

$$
\left\langle\mathbf{n}_{C}^{\prime 2}\right\rangle=4 \times\left\langle\mathrm{n}_{M}^{2}\right\rangle \times\left\langle\Delta C^{2}\right\rangle
$$

where $\Delta C$ is the standard deviation of tracer variations within the layer and the factor of 4 accounts for possible correlations between the zonal average and horizontal eddy component. The average tracer concentration $(\bar{C})$ in each layer was used for defining the anomaly equations. Expression (A11) relies on the assumptions listed above. It is no more than a best guess, which turns out to produce consistent results (in terms of uncertainties) when used in the inversion. The main test of consistency comes from the fact that the residuals of all conservation equations are indistinguishable from zero within a posteriori error bars.

Acknowledgments. We are grateful to B. Warren, P. Robbins, G. Johnson, H. Bryclen, M. Fieux, T. McDougall, R. Molcard, and an anonymous reviewer for their valuable advice and comments on the manuscript. I2, I3, and I4 were obtained from the WHPO data center with permission of the respective principal investigators (PIs) B. Warren, G. Johnson, W. Nowlin, and J. Toole. 110 was provided by G. Packard with permission of the PIs J. Toole, N. Bray, and J.Sprintiall. The data from the Franco Indonesian JADE cooperation were provided by $M$. Fieux and A. G. Tlahude (PIs); B. Coste and C. Coatanoan provided nutrient data. S. Jayne and R. Tokmakian provided the GCM fields for the error analysis. A. Macdonald advised on the inverse model; D. Spiegel and B. Brown helped with the graph- 
ics. Nentral surfaces were computed with the Jackett et al. [1997] software, and we extensively used the SEAWATER routines of P. Morgan (CSIRO). Supported in part at MIT by the Jet Propulsion Laboratory, the American Anto Manufacturers Association through the MIT Center for Global Change Sciences, and grant OCE-9617570 from the National Science Foundation (J.M.). J.M.T. acknowledges NSF grants OCE-9401343 and OCE-97010102.

\section{References}

Anderson, L. A., and J. L. Sarmiento, Redfield ratios of remineralization determined by nutrient data analysis, Global Biogeochem. Cycles, $8,65-85,1994$.

Banmgartner, A., and E. Reichel, The World Water Balance, Elsevier Sci., New York, 1975.

Beal, L. M., and H. L. Bryden, Observation of an Agulhas undercurrent, Deep Sea Res., Part I, 44, 1715-1724, 1997.

Bohren, C. F., and B. A. Albrecht, Atmospheric Thermodynamics, 402 pp., Oxford Univ. Press, New York, 1998.

Bray, N. A., S. E. Wijffels, J. C. Chong, M. Fieux, S. Hautala, G. Meyers, and W. M. I. Morawitz, Characteristics of the Indo-Pacific Through flow in the eastenn Inclian Ocean, Geophys. Res. Lett. 24, 2569-2572, 1997.

Broecker, W. S., "NO", a conservative water-mass tracer, Earth Planet. Sci. Lett. 23, 100-107, 1974.

Broecker, W. S., T. Takahashi, and T. Takahashi, Sources and flow patterns of deep-ocean waters as deduced from potential temperature, salinity, and initial phosphate concentration, J. Geophys. Res., 90, 6925-6939, 1985.

Coatanoan, C., Propriétes hydrologiques et biogéochimiques des masses d'eau dans la région Est de I'Océan Indien: Analyses saisonière et multiparamétrique des campagnes JADE 1989 et 1992, Ph.D. thesis, 185 pp., Université AixMarseille II, France, 1997.

da Silva, A., C. Young, and S. Levitus, Revised surface marrine fluxes over the global oceans: the UWM/COADS datia set, in WCRP Workshop on Air-Sea Flux Fields, pp. 13-18, DYNAMO 1997 Sci. Rep. Ni, Inst. für Meereskunder, Kiel, Germany. 1996

DeNaster, D. J., The supply and accumulation of silica in the marine environment, Geochim. Cosmochim. Acta, 45, 1715-1732, 1981.

Dickson, R. R., Flow statistics from long-term current-meter moorings, the global data set in January 1989, WOCE Rep. 40/90, WOCE Int. Proj. Off., MAFF Direct. of Fish. Res., Lowestoft, Suffolk, England. 1989.

DiMarco, S. F., W. D. Nowlin, Jr., and P. Chapman, Properties and transport of the Mozambique Channel, in 1998 U.S. WOCE R.eport, Implementation rep. 10, pp. 34-35, U.S. WOCE Off., Dep. of Oceanogr., Tex. A\&M Univ., College Station. 1998.

Donguy, J.-R., and B. Piton, The Mozambique Channel revisited, Oceanol. Acta, 14, 546-558, 1991.

Fieux, M., F. Schott, and J. C. Swallow, Deep boundary currents in the western Indian Ocean revisited, Deep Sea Res., 33, 415-426, 1986.

Fieux, M.; C. Andrié, P. Delecluse, A. G. Ilaude, A. Kartavtseff, F. Mantisi, R. Molcard, and J. C. Swallow, Measurenents within the Pacific--Indian Oceans Throughflow region, Deep Sea Res., Part I, 4, 1, 1091-1130, 1994.

Fieux, M., R. Molcard, and A. G. Ilahude, Geostrophic transport of the Pacific-Indian Oceans Throughflow, $J$. Geophys. Res., 101, 12,421-12,432, 1996.

Fu, L. L., Mass, heat and freshwater fluxes in the south Indian Ocean, J. Phys. Occanogr., 16, 1683-1693, 1986.

Ganachaud, A., Large scale oceanic circulation and fluxes of freshwater, heat, nutrients and oxygen, Ph.D. thesis, 267 pp., Mass. Inst. of Technol./Woods Hole Oceanogr. Inst. Jt. Program, Cambridge, 1999.

Ganachand, A., and C. Wunsch, Improved estimales of global ocean circulation, heat transport and mixing from new hydrographic measurements, Nature, in press, 2000.

Carrett, C., and W. Munk, Space-time scales of internal waves, Geophys. Fluid Dyn., 3, 225-264, 1972.

Godfrey, J. S., The effect of the Indonesian Throughflow on ocean circulation and heat exchange with the atmosphere: A review, J. Gcophys. Res., 101, 12,217-12,237, 1996.

Gordon, A. L., S. Ma, D. B. Olson, P. Hacker, A. Ffield, L. D. Talley, D. Wilson, and M. Baringer, Advection and diffusion of Indonesian Throughflow water within the Indian Ocean South Equatorial Current, Geophys. Res. Lett., 24, 2573-2576, 1997.

Gordon, A. L., R. D. Susanto, and A. Ffield, Throughtfow within the Makassar Strait, Geophys. Res. Lett., 26, 33253328, 1999.

Gründlingh, M. L., On the winter flow in the southern Mozambique Chamnel, Deep Sea Res., Part A, 40, 409$418,1993$.

Haine, T. W. N., A. J. Watson, M. I. Liddicoat, and R. R. Dickson, The flow of Antarctic bottom water to the sonthwest Indian Ocean estimated using CFCs, J. Geophys. Res., $103,27,637-27,653,1998$.

Hastenrath, S., and L. Greischar, The monsoonal heat buclget of the hydrosphere-atmosphere system in the Indian Ocean sector, J. Geophys. Res., 98, 6869-6881, 1993.

Hsiung, J., Estimates of global oceanic meridional heat transport, J. Phys. Oceanogr., 15, 1405-1413, 1985.

Jackett, D. R., and T. J. McDougall, A neutral density variable for the world's oceans, J. Phys. Occanogr., 27, 237263, 1997.

Jayne, S. R., Dynamics of global ocean heat transport variability, Ph.D. thesis, 150 pp., Mass. Inst. of Technol./Woods Hole Oceanogr. Inst. Jt. Program, Cambridge, Mass., 1999.

Johnson, G. C., D. L. Musgrave, B. A. Warren, A. Ffield, and D. B. Olson, Flow of bottom and deep water in the Amirante Passage and Mascarene basin, J. Geophys. Res., 108, 30,973-30,984, 1998.

Jourdan, D., P. Peterson, and C. Gautier, Oceanic freshwater budget and transport as derived from satellite radiometric data, J. Phys. Oceanogr., 27, 457-467, 1997.

Kalnay, E., et al., The NCEP/NCAR 40-year reanalysis project, Bull. Am. Meteorol. Soc., 77, 437-471, 1996.

Lee, T., and J. Marotzke, Inferring meridional mass and heat transports of the Indian Ocean by fitting a general circulation model to climatological data, J. Geophys. Res., 102, 10,585-10,602, 1997.

Lee, T., and J. Marotzke, Seasonal cycles of mericlional overturning and heat transport of the Indian Ocean, J. Phys. Oceanogr., 2S, 923-943, 1998.

Lutjeharms, J. R. W., The Agulhas Current system during the northeast monsoon season, J. Phys. Oceanogr, 6, 665670,1976

Macdonald, A., Oceanic fluxes of mass, heat, and freshwater: A global estimate and perspective, $\mathrm{Ph} . \mathrm{D}$. thesis, Mass. Inst. of Technol./Woods Hole Oceanogr. Inst. Jt. Program, Cambridge, 1995.

Maccionald, A., The global ocean circulation: A hydrographic estimate and regional analysis, Prog. Oceanogr., 41, 281--382, 1998.

Macdonald, A. M., and C. Wunsch, An estimate of global ocean circulation and heat fluxes, Nature, 382, 436-439, 1996.

McDougall, T., Neutral surfaces, J. Phys. Oceanogr., 17, 1950-1964, 1987

McDougall, T. J., Parameterizing mixing in inverse models, 
paper presented at Parameterization of Small-Scale Processes, Hawaiian Winter Workshop, Univ, of Hawaii at Manoa, 355-386, 1991.

McIntosh, P. C, and S. R. Rintoul, Do inverse box models work?, J Phys. Oceanogr., 27, 291-308, 1997.

Ménaché, M, Première campagne océanographique du Commandant Robert Giraud clans le canal de Mozambique, 11 octobre au 28 novembre 1957, Cah. Océanogr., 15, 224-237, 1963 .

Meyers, G., R. J, Bailey, and A. P. Worby, Geostrophic transport of Indonesian Throughflow, Deep Sea Res., Part I, 42, 1163-1174, 1995 .

Minster, J.-F, and M. Boulahdid, Redfield ratios along isopycnal surfaces-A complementary study, Deep Sea R.es., 34, 1981-2003, 1987.

Munk, W, and $\mathrm{C}$. Wunsch, The Moon and mixing: Abyssal recipes II, Deep Sea, Res., Part I, 45, 1977-2010, 1998.

Oberhuber, J. M., An atias based on the COADS data set: The budgets of heat, buoyancy and turbulent kinetic energy at the surface of the global ocean, technical report, Max-Planck-Inst. für Meteorol., Hamburg, Germany, 1988.

Polzin, K. L., J. M. Toole, G. R. Ledwell, and R. W. Schmitt, Spatial variability of turbulent mixing in the abyssal ocean, Science, 276, 93-96, 1997.

Redfield, A. C., B. H. Ketchum, and F. A. Richards, The influence of organisms on the composition of sea water, in The Sea, vol. 2, edited by M. N. Hill, pp. 26-77, Wiley Interscience, New York, 1963.

Robbins, P. E., and J. M. Toole, The dissolved silica budget as a constraint on the meridional overturning circulation in the Indian Ocean, Deep Sea Res., Part I, 44, 879-906, 1997 .

Sxtre, R., and A. J. da Silva, The circulation in the Mozambique Channel, Deep Sea Res., 31, 485-508, 1984.

Schmitz, W. J., Jr., On the world occan circulation, vol. II, The Pacific and Indian Oceans / A global update, Tech. Rep. WHOI-96-08, Woods Hole Oceanogr. Inst., Woods Hole, Mass., 1996.

Schott, F. S., M. Fieux, J. Kindle, J. Swallow, and R. Zantopp, The boundary currents east of Madagascar. 2. Direct measurements and model comparisons, J. Geophys. Res., 93, 4963-4974, 1988.

Schott, F., J. C. Swallow, and M. Fieux, The Somali Current at the equator: Annual cycle of currents and transports in the upper $1000 \mathrm{~m}$ and connection to neighbouring latitudes, Deep Sea Res., Part A, 37, 1825-1848, 1990.

Semtner, A. J., Jr., and R. M. Chervin, Ocean general circulation from a global eddy-resolving model, J. Geophys. Res., 97, 5493-5550, 1992.

Siefridt, L., B. Barnier, KK. Béranger, and H. Roquet, Evaluation of operational ECMWF surface heat fluxes: Impact of parameterization changes during 1986-1995, J. Mar. Syst., 19, 112-135, 1999.

Stammer, D., R. Tokmakian, A. Semtner, and C. Wunsch, How well does a $1 / 4^{\circ}$ global circulation model simulate large scale oceanic observations?, J. Geophys. Res., 101, $25,779-25,811,1996$.

Stramma, L, and J. Lutjerharms, The flow field in the subtropical gyre of the south Indian Ocean, J. Geophys. Res., $102,551.3-5530,1997$.

Toole, J., and B. A. Warren, A hydrographic section across the subtropical south Indian Ocean, Deep Sea Res., Part $I, 40,1973-2019,1993$.

Wajsowicz, R. C., A relationship between interanumal variations in the South Pacific wind stress curl, the Indonesian Throughflow, and the western Pacific warm pool, J. Phys. Oceanogr., 24, 2180-2187, 1994.

Wajsowicz, R. C., The response of the Indo-Pacific throughflow to interannual variations in the Pacific wind stress, II, Realistic geometry and ECMWF wind stress anomalies for 1985-1989, J. Phys. Oceanogr., 26, 2589-2610, 1996.

Warren, B. A., Trans-Indian hydrographic section at lat. 18 degrees S: Property distributions and circulation in the south Indian Ocean, Deep Sea Res., Part A, 28, 759-788, 1981.

Warren, B. A., Approximating the energy transport, across oceanic sections, J. Geophys. Res., 104, 7915-7919, 1999.

Warren, B. A., and C. G. Johnson, Deep currents in the Arabian Sea in 1987, Mar. Geol., 104, 279-288, 1992.

Wijffels, S. E., Exchanges between hemispheres and gyres: $A$ direct approach to the mean circulation of the equatorial Pacific, Ph.D. thesis, 297 pp., Mass. Inst. of Technol./Woods Hole Oceanogr. Inst. Jt. Program, 1993.

Wijffels, S. E., R. W. Schmitt, and H. L. Bryden, Transport of freshwater by the oceans, J. Phys. Oceanogr., 22, 155$162,1992$.

Wunsch, C., The Ocean Circulation Inverse Problem, 437 pp., Cambridge Univ. Press., New York, 1996.

Wyrtki, K., Oceanographic Atlas of the International Indian Ocean Expedition, Amerind, New Delhi, 1970.

You, Y., Dianeutral mixing, transformation and transport of the deep water of the Indian Ocean, Deep Sea Res., Part I, 46, 109-148, 1999.

Zhang, K. Q., and J. Marotzke, The importance of openboundary estimation for an Indian Ocean GCM-data synthesis, J. Mar. Res., 57, 305-334, 1999.

A. Ganachaud, UM/LPO IFREMER 29280 Plouzané, France. (Alexandre.Ganachaud@ifremer.fr)

J. Marotzke, School of Ocean and Earth Science, SOC 566/11, University of Southampton, Southampton Oceanography Centre, Southampton SO14 3ZH, U.K.

J. Toole, Woods Hole Oceanographic Institution, MS 21, Woods Hole, MA 02543.

C. Wunsch, 54-1521 Massachusetts Institute of Technology, 77 Massachusetts Avenue, Cambriclge, MA 02139.

(Received June 18, 1999; revised April 25, 2000; accepted June 7, 2000.) 